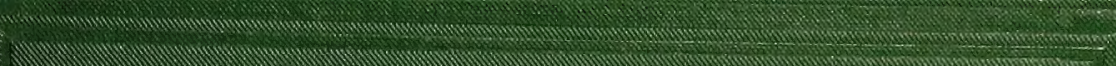

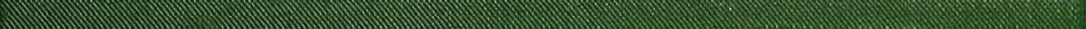

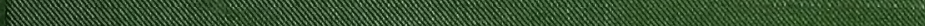




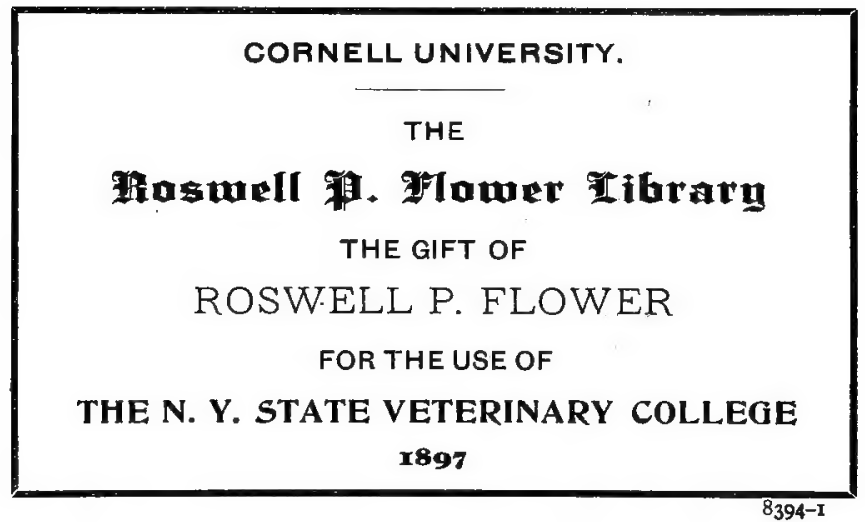


Spring-time surgery

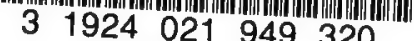

49320 ves 


\section{Cornell University Library}

The original of this book is in the Cornell University Library.

There are no known copyright restrictions in the United States on the use of the text.

http://www.archive.org/details/cu31924021949320 




\title{
Veterinary Medicine Sertes
}

No. 1

\section{SPRINGTIME SURGERY}

\author{
Edited by \\ D. M. Campbell, D.V.S. \\ Editor, American Journal of Veterinary Medicine
}

THIRD EDITION

REVISED AND ENLARGED

Chicago

American Journal of Veterinary Medicine

1913 

Copyright, 1913

D. M. Campbell

The Rajput Press, Chicago 


\section{PREFACE TO THIRD EDITION}

Advantage has been taken of the exhaustion of the last edition to correct a few typographical errors and, at the suggestion of the authors, to make slight changes in some of the articles.

The remarkable sale of this work has made necessary the third edition, within a year from the date of its first publication. There are many evidences that it has proven helpful to a large number of veterinarians and that this edition will meet with the cordial response given its predecessors.

The EDITor.

Chicago, March 1913. 


\section{Veterinary Medicine Series}

No. 1

\section{PREFACE TO SECOND EDITION}

The fact that a second edition, of a veterinary publication, should be required, within thirty days from the time the first edition was received from the bindery-thus establishing a new record among veterinary publications-is proof positive of its usefulness and its welcome. SPRINGTIME SURGERY has had this remarkable sale. A higher commendation is scarcely possible, a further one unnecessary.

This work is unique, an innovation in veterinary literature, and has appealed strongly to practising veterinarians. The thanks of the editor, and all credit for the usefulness of SPRINGTIME SURGERY, are due to the contributors who have given of their time and talents for the enlightenment of the Profession.

Three articles have been included in this that are not contained in the former edition, two in the former have been omitted from this edition. A number of those in the first edition have been thoroughly revised for this one by the authors.

THE EDITOR.

Chicago, April, 1912. 


\section{SUCCESS}

Pluck will win-its average is sure, He wins the fight who can the most endure. Who faces issues, he who never shirks, Who waits and watches and who always works. (Author unknown). 


\section{PREFACE TO FIRST EDITION}

There is an obvious advantage in having grouped, in one small volume, really meritorious discussions of the cases most common at any season. The articles in this book, which are reprinted from the American Journal of Veterinary Medicine, constitute, we believe, the most instructive yet brief description, and the most helpful case-reports to be gleaned from the literature on the surgical and obstetric problems common during the foaling and castrating season. The discussions of "Springtime Surgery," while in no sense exhaustive, yet constitute, for the practising veterinarian, a valuable supplement to the standard textbooks of veterinary surgery and obstetrics.

The superior merit of these articles amply justifies their reproduction in a form more permanent than is offered by magazine publication. The frequent requests from subscribers for copies of the issues of "Veterinary Medicine" containing various of these articles convinces us, that their presentation in book form will be welcomed by a large number of veterinarians and that this volume will be of much usefulness in this field.

Chicago, March, 1912.

THE EDITOR. 


\section{TABLE OF CONTENTS}

Castration of Cryptorchids .... sht...... 9

Practical Methods of Cryptorchidectomy... 39 Cryptorchidectomy in Horses . . . . . . 75 An Interesting Monorchid t... . . . 4..... 83 A Castrator's Error ..... rest. . . . . . . 87 Hemorrhage After Castration ............ 91 Castration of Pigs Having Scrotal Hernia?.M. 93 Operation on a Hermaphrodite 0.2 . Che.de.5. . . 97 Spaying Heifers on Western Ranches.

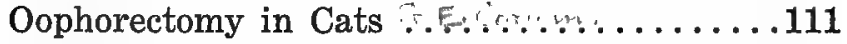
Prolapsus Uteri: Its Successful Treatment..113 Unusual Case of Obstetrics $\therefore \ldots \ldots \ldots \ldots .116$ Proper Replacement of the Everted Uterus. .117 Pervious Urachus ........... .120 Care of Navels in Newborn W. W. Superfetation with Report of a Case . . . . . . : 133 Atresia Ani ........................137 Treatment of Contracted Tendons in Foals...141 Minor Means of Restraint ...............145 The Treatment of the Injured Hand Fin 153 


\section{Castration of Cryptorchids}

By W. L. WILliaMS, V. S., Professor of Surgery and Obstetrics in the New York State Veterinary College, Cornell University, Ithaca, New York, author of

"Veterinary Obstetrics," "Surgical and Obstetric Operations," etc.

It is generally considered advisable to castrate all male domestic animals which are to be regularly used for work or as human food. However true this may be of normal males, it is emphasized in most cases of cryptorchids or hidden testes.

It is especially desirable that the cryptorchid, or the monorchid, be castrated, in order that he may not be used for breeding purposes, because he may largely transmit the defect to his offspring. In addition to this, the abdominal testicle usually induces a perverted sexual desire, closely analogous to the nymphomania of the female.

*Reprinted from the Missouri Valley Veterinary Bulletin, April, 1910. 
Etiology.-The causes of cryptorchidy are various, and are not wholly understood. We meet with three groups of causes or conditions which are of interest:

1. Arrested development, or descent of the organ.

2. Aberration of the development of the organ -teratoma.

3. Pathologic conditions of the testes.

In the first case, the testicle forms normally, and drops from its embryonic location into the peritoneal cavity, but fails to descend into the scrotum. It then retains its fetal character, is small, soft, flaccid and histologically shows the fetal spermatoblasts, but no spermatozoa. The gland is therefore without procreative function, but induces often a sexual mania. Its position varies, being located at any point on a line passing from the embryonic seat, near the posterior end of the kidney, to and into the internal in guinal ring.

The second class, the teratoma, comprises a widely varying group of dermoid cysts, of almost any dimensions and containing epidermal 
debris and structures, such as hair, dental tissues, etc. They are highly interesting because they suggest that the sexual glands are really of epiblastic origin, as contended by some embryologists, instead of mesoblastic, as asserted by most authorities.

The third group comprises extremely variable pathologic changes, such as cystic, calcareous or other forms of degeneration, malignant newgrowths, etc.

These three groups are known to be of very unequal size, though definite data as to the proportions of each are wanting. Ninety-one cases have been operated upon in our clinic, of which ninety belonged to the first group, none to the second, and one to the third. In private practice we have met with one additional case of pathologic testicle, but no teratoma.

The teratoma are considered so unusual that - they are largely recorded, and probably an exaggerated idea of their prevalence is acquired. It is highly important that these three classes be kept in mind, since they have an essential bearing upon the surgical procedure in castration. 
Other less essential elements entering into the surgical problem of cryptorchidy are whether the testicle is abdominal or inguinal in location, and to what species the animal belongs.

Cryptorchid castration, like many surgical procedures, was at first chiefly empiric in character, and in fact is still largely practiced as an empiric operation, the operation being largely taught and learned in a manner devoid of scientific knowledge.

Preparation.-The preparation of an animal for the cryptorchid operation does not differ materially from the general rule for other abdominal operations. We desire that the patient shall be in prime physical condition, having had abundant exercise or work to place him in good, vigorous health. Before the operation, the alimentary tract should be emptied either by restricted diet or by hypodermic catharsis. Fullness of the alimentary tract should be obviated for general surgical reasons and for the special purpose of facilitating the operation, by affording greater intra-abdominal room and preventing prolapse of abdominal viscera through the wound. 
Control.-The securing of the patient, in case of the horse, needs be either in dorsal recumbency, or in the lateral position, with that side upon which the hidden testicle is located, uppermost. There is but one essential detail in securing the horse: The thigh on the side of the hidden testicle must be fully abducted. This may be effectively accomplished by many methods of casting, and may be perfectly attained upon some types of operating table.

If the thigh is not completely abducted, the operator may find his hand so compressed that it is soon fatigued and disabled, and the operator confused and lost. It is a great error to attempt the operation except this abduction is complete and secure. Should the apparatus slip during the operation, and the operator's hand become compressed, it is liable to greatly confuse even an experienced surgeon.

The question of general anesthesia is one upon which operators may justly differ. For the beginner, it is the best way. The beginner may, under proper aseptic precautions, manipulate an anesthetized cryptorchid for half an hour or an 
hour, without serious harm to the patient, and without seriously transgressing the general sentiment of humanity for animals, which is developing so rapidly amongst our people. Anesthesia is also highly important for the experienced operator. The inguinal region needs to be kept as freely open and the tissues as passive as possible, this can be attained only by general anesthesia.

When the beginner is working upon an anesthetized patient, he is relieved from the disturbances of change in position and the shifting in the relations of parts. The abdominal viscera are not forcibly pushed against his hand or through the opening. It is of great importance also that the beginner should be relieved, through the general anesthesia of his patient, from the confusing and enervating mental anxiety caused by the pain he is otherwise inflicting upon the patient, as expressed by violent struggling, sweating, groaning, etc.

Again, general anesthesia is always best, even for the experienced operator in all cases of complications, and the surgeon rarely knows that a case is complicated until deeply in the operation, 
where he cannot retreat or readily modify his plans. We believe in general anesthesia in all cases.

Diagnosis.-Some advise rectal exploration prior to securing the patient for operation. The procedure has certain value. In those cases of monorchidy where the scrotal testicle has been removed (a very unfortunate and inadvisable procedure), the operator may determine definitely upon which side the hidden testicle is located. It may further give him important information as to whether the retained gland falls within our first, second, or third class. Should it belong to the second or third class, the examination reveals to the operator the nature of the conditions, forewarns him of the obstacle to be overcome, and enables him to plan his operation.

On the whole, rectal exploration prior to operation is largely impracticable. It is generally inconvenient to make such examination until immediately prior to the operation, and at that time, it is as a rule imprudent because of the difficulty of cleansing the hands properly after they have been soiled by feces. 
Asepsis and Disinfection.-Another point of very great importance is the question of disinfection of the operative area, and the maintenance of asepsis. The problem is somewhat alike, whether the incision be made in the scrotal, inguinal, prepubian or flank region. In the horse, the incision is usually made in the scrotal or inguinal region, while in other animals it is best made in the upper flank. While the skin of the scrotal and inguinal regions is very thin, soft, and usually almost hairless, it is nevertheless thickly covered with sebum, which is very insoluble and difficult to remove. Washing for a few minutes with any ordinary antiseptic, even though preceded by soap and warm water, is of scant, if any value. The problem of the practical disinfection of this region has not been solved. The profuse application of alcoholic or ethereal solutions excoriate the delicate skin.

Careful investigations need be made toward solving this problem. Possibly a good method would be to wash the parts thoroughly, an hour or two prior to the operation, with,soap and hot water, perhaps mixed with kerosene in emulsion, 
or with lysol, bacterol, or carbolic acid. The sheath being always dirty bacteriologically, the smegma from this should be carefully cleared away, and the sheath and prepuce anointed with an antiseptic oil, glycerin or vaseline. The skin having been allowed to dry completely, when the patient is secured for the operation, the operative area may be liberally covered with tincture of iodine, and allowed to dry before making the incision. After the skin incision has been made, additional security might be attained by again applying the tincture of iodine to the margins of the cutaneous wound.

Incision.-Some operators make their incision through the skin and dartos in the scrotal region, parallel to the median raphe and one to two inches laterally therefrom. Others make their incision directly over the external inguinal ring and in the same direction. By the first method, the operator inserts his hand through the wound in the skin and dartos, divides the loose areolar connective tissue and pushes aside the numerous vessels, in an upward and outward direction until he reaches the external inguinal ring immediately at that 
point at which the second operator would make his incision.

The incision over the external ring is therefore more direct and the resulting wound less extensive, in which respect it is more conservative and preferable. The scrotal incision has the important advantage over the inguinal, in that the inevitable movements of the thigh after the operation disturb the cutaneous wound over the inguinal ring, but do not seriously involve the scrotal wound. We prefer the scrotal incision.

Inguinal Cryptorchidism. - Having reached the loose areolar tissue in the external abdominal ring, whether indirectly through a scrotal incision or directly through an inguinal wound, the operator, with his fingers in the form of a cone, and by means of a rotary motion, pushes the areolar tissues aside and cautiously advances his hand upwards, outwards and slightly forwards toward the internal inguinal ring, or the position which it should occupy. Care should be taken to note here the presence or absence of a distinguishable gubernaculum testis, of the epididymis or of the testicle itself. 
If a recognizable gubernaculum is present, it may be an important guide to the internal ring, and hence an aid of value to the operator, especially to the beginner; or the operator, by grasping this and drawing upon it, may bring the testicle out through the ring and grasp it. Usually the presence or absence of this structure in a recognizable form may be suspected by the presence or absence of a distinct dimple or depression at the fundus of the scrotum.

When the epididymis has descended into the scrotum, it is recognized as a somewhat firm cord about the size of a man's finger, and is well nigh indistinguishable from the stump of the spermatic cord following castration. It is more free from adhesions to surrounding tissues, and its obtuse extremity is connected with the skin and dartos only by the indistinct gubernaculum. Cutting through the peritoneal sheath of the cord, the operator exposes the vas deferens and tail of the epididymis firmly attached, naturally, not by adhesions, at the distal end of the tubular cord. By exerting traction upon the tail of the epididymis, the head of that organ may be brought into 
view, the entire epididymis being abnormally elongated and attenuated. The testicle itself remains firmly lodged above the internal ring, or incarcerated in it, and, however much traction may be exerted on the epididymis, the gland usually remains immovably fixed.

The first case of this kind with which we met led us into error, and we removed the epididymis and a portion of the vas deferens, while we left the testicle in the abdomen. Later in our clinic we operated upon a case, the history of which could not be traced, but which had evidently been operated upon by some one who had fallen into the same error, removing the epididymis and leaving the testicle. The condition offers some difficulty to overcome. The most direct method is to freely incise the peritoneal sheath down to the internal ring and either dilate this by forcing the finger through the ring along side of the vas deferens and epididymis, or by cautiously incising the ring with a scalpel or bistoury. The testicle may then be withdrawn and removed.

If the testicle itself is encountered in this region (inguinal cryptorchidism) the gland is to be 
seized and forcibly brought out through the wound. Having passed through the internal ring, the gland is covered by the cremasteric fascia or tendon and by the parietal peritoneum, which are to be incised as soon as brought to view, and the testicle laid bare. It is to be noted that in all cases of abdominal cryptorchidism, including those we have mentioned where the epididymis has descended into the scrotum, the testicle, when brought out, is naked; while in inguinal cryptorchidism, the testicle is inevitably brought out covered by the cremasteric structures and the parietal peritoneum.

Locating the Internal Inguinal Ring.Encountering neither gubernaculum, epididymis or testicle in the inguinal region, the operator should search for and locate the internal abdominal ring, whether he designs to penetrate it or not, as it constitutes the immediate, logical guide to the location of the testicle.

This ring may usually be recognized in the cryptorchid horse, as an elliptical slit, appearing to the touch as about three-fourths to one and one-fourth inches long by one-half inch wide, 
directed obliquely forward and outward in its greater diameter. It is covered by a thin layer of peritoneum, while its margins, the borders of the great and small oblique muscles, are distinguished by their greater thickness and firmness. This ring is located two to four inches upward, outward and slightly forward from the external abdominal ring. It is just opposite and very near to the crural ring, and, by palpating outward against the thigh, the operator easily recognizes the pulsating femoral artery as it emerges from the crural ring.

In some cases the internal ring is unrecognizable by palpation, but the determination of its approximate location is nevertheless essential to scientific cryptorchid castration. The recognition of the ring is especially difficult in animals previously operated upon unsuccessfully, and followed by the formation of a large amount of dense, cicatricial tissue. When the ring has been recognized, if the operator will approximate his thumb, index, and second fingers to constitute an incomplete circle of one to two inches in diameter and press the ends of the digits against the abdom- 
inal muscles about the margins of the ring, the peritoneal curtain closing the ring, the processus vaginalis, tends to push outward in the form of an obtuse cone, while enclosed within it are the gubernaculum and usually the tail of the epididymis and the base of the vas deferens. The gubernaculum, in its intra-abdominal position, is recognized, as a somewhat distinct, firm, straight cord, about one-eighth of an inch in diameter, somewhat movable within the peritoneum. The two latter are recognizable as hard dense, coiled cords or filaments, which are readily grasped beween the thumb and fingers, and clearly recognized by palpation.

Securing the Testicle.- These facts we have found of the greatest importance in the clinical teaching of the operation. It is the keynote in our method of instruction. We advance the operation to this point, seize the processus vaginalis enclosing the gubernaculum, the vas deferens or the tail of the epididymis between the thumb and fingers, introduce a long pair of forceps, and seize the gubernaculum, epididymis or vas deferens, still covered by the peritoneum. We then 
secure the forceps in this position, with the desired structure firmly caught, and the beginner introduces his hand, palpates all the parts, ruptures the peritoneum, grasps the gubernaculum . and then the vas deferens, followed by the epididymis, and completes the operation.

Reaching and recognizing the internal ring, operators divide themselves into two or more groups in their further procedure.

We recommend, in those cases we have just mentioned, in which the operator can grasp the vas deferens or epididymis outside the ring in the processus vaginalis, still covered by the peritoneum, that the peritoneal covering be ruptured by dragging upon it, the tail of the epididymis grasped and drawn out and the testicle itself brought out by traction upon the epididymis, thus completing the operation without the insertion of the hand or even of a finger into the abdominal cavity. In some cases, the testicle may not be drawn through the narrow ring by traction alone, in which instances we insert an index finger, dilate the ring, and, exerting traction on the epi- 
didymis with the other hand, guide the gland through the ring with the introduced finger.

Should we be unable to grasp the epididymis outside the ring, we penetrate the ring with an index finger, and, directing it backward, hook the index finger over the gubernaculum as it leaves the posterior margin of the ring, to immediately lose itself in the tail of the epididymis. This is grasped, drawn through the ring, and the operation then proceeds as before.

Should the operator fail to locate the ring, he needs at least to determine its approximate location, penetrate the muscular wall as near to the normal position of the ring as he can determine with his index finger, and, palpating the surface of the peritoneum, locate and grasp the gubernaculum, and eventually the vas deferens.

Theoretically, should the operator fail to locate the testicle by this plan, he should next introduce the entire hand into the peritoneal cavity, again search for the gubernaculum, the epididymis, and especially for the gland itself, and as a final resort search for the vas deferens about the urethra and trace it back to the gland. 
Practically, when an operator must insert his entire hand into the abdominal cavity in his search for the testicle, it is the operator, and not the testicle, which is lost, with often a far too poor prospect of finding himself and recognizing the definitely located and attached organ.

Too many operators, and especially beginners, search for, and attempt to identify the testicle, without considering the relations to the gland of the gubernaculum and vas deferens. Searching independently of these for the gland is like a shore fisherman on a dark night, who has securely hooked and landed a fish in the darkness, and starts groping about to find it, instead of following his pole to the line, and thence along the line to the hook, where the fish is definitely fixed and located. So, in castrating a cryptorchid, the testicle need not be "found" in the common mean= ing of the word, because it is not "lost," for the epididymis and vas deferens are definitely and closely moored at the posterior commissure of the internal ring by the gubernaculum and at the proximal end of the epididymis, securely fixed, is the gland itself. 
Going back to the course of the operation, when the operator has reached the internal ring or its immediate vicinity, many operators diverge from the technic we have recommended.

Instead of penetrating the ring, they push somewhat upward and forward and penetrate the fascia of the small oblique muscle. By this plan, the insertion of at least one finger in the abdominal cavity is necessitated, which, by the direct method we have suggested, may be obviated. Beyond this, the operation is identical.

It is, we believe, erroneously contended by the advocates of this plan that prolapse of the abdominal viscera is thereby obviated. The only cases of visceral prolapse from cryptorchid castration observed in our clinic have been patients operated upon by experienced castrators who were uncompromising devotees to this plan, and applied the technic in their operations.

In the ordinary cryptorchid castration, where the testicle is small and flaccid, and where it is drawn through the ring by traction on the vas deferens and epididymis or the withdrawal is supplemented by the very slight dilation of the ring 
by the insertion of one finger, the danger from visceral prolapse is very remote. We have not observed the accident under these conditions.

If the entire hand is forced through the ring, admittedly there is danger of prolapse. If the entire hand is forced through the fascia of the small oblique above and anterior to the internal ring or elsewhere in the vicinity, the inevitable rent will pass down, and involve, or pass alongside the ring and produce a tear essentially identical with that caused by forcing the hand directly through the ring.

Pathologic Testicles. - Should the testicle fall within the second or third class we have mentioned, and be greatly enlarged, so that it must be removed entire, it matters little whether the internal ring is enlarged to permit its escape or the same sized opening is made in close proximity to the ring. There results a great rent through which visceral prolapse is highly probable. Should the operator know in advance that he has a testicle of extraordinary size to deal with, he should abandon the inguinal route and choose the upper flank as the safer and better. 
Indeed, under modern surgical technic, the flank operation is in any case quite as safe as the inguinal, whenever the operator inserts his hand into the peritoneal cavity.

Should the testicle be in a pathologic state, and adherent to the intestines or other viscera, the flank operation is advisable or even necessary. In the one pathologic testicle removed in our clinics, the patient being a pig, the testicle was firmly adherent to two loops of small intestine. It was necessary to draw these out with the gland and dissect them away.

In other animals than the horse, we constantly prefer the flank operation, except we can recognize the epididymis in the inguinal region, and draw the gland out by traction.

Laparotomy.-For the flank operation, the patient is secured in lateral recumbency with the head end inclined, the flank shaved and disinfected, and an incision is made as for flank spaying, of a size to admit one finger or the entire hand, according to the conditions.

In small pigs and dogs and cats we have found the small wound sufficient. In large boars we 
have been forced to make the opening large enough to admit the hand.

Inserting the index finger, or the entire hand, the operator frequently recognizes the gland at once, lying just by the incision. Otherwise he reaches the inguinal ring, grasps the gubernaculum, glides along it to the epididymis, and thence to the testicle.

Double Cryptorchids-In double cryptorchidism in small animals, both testes may be removed through one incision, or, having opened the wrong flank when but one gland is retained, he may still complete his operation through the erroneous incision. He merely needs pass his index finger, or his hand, along the floor of the abdomen, across to the opposite inguinal ring, grasp the gland, draw it across to the other side and out through the incision.

So, in the cryptorchid horse, if he is a double cryptorchid and the operator has inserted his entire hand in order to secure the first testicle, he should not make a second wound, but reach across beween the viscera and abdominal floor, seize the second testicle and remove it through 
the first wound. Likewise, in operating upon a horse with one abdominal testicle, where the scrotal testicle has been removed, and the operator errs by cutting in upon the wrong side and has inserted his hand into the peritoneal cavity, he should not make a second wound, but remove the testicle through the wound already made.

After Treatment.-After a cryptorchid testicle has been withdrawn from the abdomen, the method of severing the cord is usually a minor matter. In our first class, which includes probably ninety-nine per cent of the cases, and in which the gland has been arrested in its development, it is comparatively non-vascular and does not bleed.

The completion of the operation may vary. In the flank operation, the abdominal wound is naturally sutured. If the inguinal operation has been cleanly accomplished with unimportant laceration of tissues and without danger of visceral prolapse, it may well be sutured. If there is danger of visceral prolapse or of serious infection, antiseptic tampons should be inserted up to the internal ring, and held in position by sutures. 
By means of large tampons, an enormous rent in the abdominal floor may be successfully closed, and prolapse obviated. In large rents, the safest way to tamponade is to take a broad and ample piece of cheesecloth, and spread it with its center over the wound. Then take masses of convenient size of gauze, cheesecloth or cotton, boiled, immersed in a disinfectant and pressed dry, and push them in to the internal ring, inside the sheet of cheesecloth. No matter should it extend a few inches into the abdomen, it cannot escape. When the wound is well filled, the tampon is secured in place by scrotal sutures.

After twenty-four to forty-eight hours, the sutures are to be removed, the packing inside the sheet of cheesecloth cautiously withdrawn, followed by the sheet of cheesecloth itself. Blood clots are then to be mopped out with antiseptic gauze, and, if deemed advisable, a new smaller tampon inserted for another day.

According to the degree of infection, the wound may be let alone or mopped out daily with swabs of antiseptic gauze, preferably saturated with tincture of iodine. The inguinal wound should 
not be irrigated, lest the antiseptic be forced into the peritoneal cavity.

Should fever arise, and not be promptly relieved by local handling of the wound, we recommend large doses of quinine or potassium iodide, usually preferring the former. To a medium sized horse we give one to three ounces of quinine daily until the fever yields or toxic effects, such as trembling or diarrhea appear, when we change to potassium iodide.

Mortality.-This is not well known in cryptorchid castration. In the ninety-one cases in our clinic there were included twenty-eight pigs, one dog and one cat, among which there were no losses.

Of the sixty-one horses, fifty-six or ninety-two per cent recovered, and five animals or eight per cent died. These losses are abnormally high. Four of the five cases succumbed to infection.

In the earlier years of our clinic, the operations were essentially all by students. In many cases, six to ten different students each inserted his hand into the inguinal wound and palpated the parts. Three of the fatal infections resulted 
from this practice. This plan was then abandoned, since which but one fatality has occurred from infection, following the operation by a member of the staff.

Hospital Infection.-In our clinic we have had another obstacle to meet. The late Professor Williams of Edinburg wrote more than a quarter of a century ago advising against the castration of horses when the wind was from the east, and to avoid operating in any kind of weather in the neighborhood of a veterinary college.

Whatever may be effect of an east wind in England, the dangers of operating in a veterinary college are not to be ignored. Prior to the days of antiseptic and aseptic surgery, surgical operations on man in hospitals were followed by an appalling mortality, but the mortality from wound infections in hospitals for man have been very largely overcome.

Veterinary surgery offers a different problem, especially in the horse, and the details of efficient asepsis and antisepsis in veterinary hospitals is not yet satisfactory. A prime difficulty in our work is cheapness in the construction and equip- 
ment of our veterinary hospitals, with limited opportunity for efficient disinfection.

From the beginning of our clinic in 1896 up to a recent date, we have noted an increased tendency toward serious infections, from the opening of the clinic in the autumn to its close in June. The hospital and operating room were then vacant and open for the summer months. In other words, the presence in the hospital and in the operating room of cases of fistulous withers, pollevil and other chronic, profusely suppurating maladies so befouled the establishment that virulent infection abounded. Our cryptorchid castrations came almost wholly toward the close of our school year, when infection of our hospital had apparently reached its highest virulence. This we have fought so energetically that we now believe we can perform most operations in our hospital with greater safety than outside, and believe we can castrate as safely as anywhere. Neither do we observe increased infection as the year advances. In fact, we last year extended our clinic to cover the entire year, and are still able to keep wound infection under satsifactory control. 
Sources of Infection.-Aside from the disinfection of the instrument and of the hands, arms and clothing of the operator, there are other neglected sources of infection which the veterinarian should recognize.

Our casting apparatus constitutes a highly dangerous bearer of virulent infections, and the body surface of the animal, with its massive coat of hair, which it is perhaps shedding, affords ample opportunity for the entrance of infection into the wounds. We should devise better means for obviating these.

Aside from infection, the mortality from cryptorchid castration is well nigh negligible. Of course, casting accidents may occur, and some losses have taken place from intestinal prolapse. The latter, can and should, always be obviated.

Complications.-Among our five deaths, one was due to an accident based upon an error. We opened the patient on the wrong side, recognized the vas deferens of the testicle which had been removed, but, before we were aware, had made a rent in its peritoneal fold. We reached across to the opposite side, grasped the testicle and re- 
moved it through the wound. A loop of the small intestine dropped through the peritoneal rent behind the vas deferens of the testicle which had been removed at a prior date, the intestine became strangulated and the patient succumbed. Had such a result been anticipated or thought of as a possibility all danger could have been obviated, after the rent had been made, by rupturing the vas deferens, thus leaving no place for the incarceration of the viscera.

So with other complications which may arise. The operator should preserve his equanimity, and, in cases of error or unexpected complications, promptly and coolly meet the conditions. To this end, the operator needs be fully prepared for emergencies, have the surroundings in all essentials suitable, have abundant help at hand, and, beyond all else, needs be in good physical condition, free from fatigue of body or mind.

In the one fatal error we have recorded, the difficulty was largely referable to the fact that the writer was ill, and should, by all rules of professional action, have been in bed instead of at the operating table. Good surgical work requires 
vigor of both mind and body, and we are forced to see this if we undertake an operation when we are unfit, and then meet with complications. 


\section{Practical Methods of Cryptorchidectomy*}

By Charles Frazier, B. Sc., M. D. V., Professor of Pathology and Bacteriology and Dean of the McKillip Veterinary College, Chicago

It is my purpose in this article to outline a technic which has given uniform success in my hands, one that is based on a thorough study of the anatomical and surgical conditions met, and one which I am sure any one can follow who has any skill whatsoever. I want at this point to emphasize the fact that the operation, as practically carried out, is a simple one.

Preparation of the Patient. - This can be summarized in one statement. Have the patient's bowels moderately full of ingesta and absolutely free from the irritability produced by cathartics, change of food and emptiness. Do not give

\footnotetext{
*Reprinted from the American Journal of Votorimary Medicine, May, 1911.
} 
cathartics of any kind; do not starve the patient and do not upset the intestinal canal by a radical change of food.

A bowel that is moderately distended with ingesta, free from all forms of irritation, in normal and perfect physical and physiological condition, is the one that is not going to be upset by any amount of clean manipulation in the abdomen and surely is not the one to prolapse most frequently. Peritoneal irritability explains in a large degree prolapses of the omentum. The omentum has been aptly called the "policeman of the belly," searching out, as it does, localized peritoneal disturbances, and through some power of its own going to such areas and attempting to cover them over by adhesions, where there is injury to or loss of the peritoneal tissue. Thus it is apt to wander down the inguinal canal at inopportune times.

Rectal Examination.- Prior to the operation this is not to be thought of as a routine practice. In animals that have had one testicle removed and a diagnosis as to the side is wanted, there is a better way of proceeding than by rectal examina- 
tion, and further, in such cases, a rectal examination by the best operators gives no positive results and frequently leads to harmful procedures. The question of the side upon which to operate is not, except very rarely, a difficult one to decide. The answer is obvious if the animal has never been operated upon or if one testicle has been removed and there is but one scar and that clearly upon one side of the scrotum. A diagnosis is to be made, not at all upon the history the owner gives, but upon one's own findings. This examination is to be made after the animal is cast, and consequently will be considered later.

Disinfection.-Antiseptic applications to the scrotum, prepuce and thighs, some hours preceding the operation, have no place in the technic. Theoretically they may be defended, but practically they cannot.

The total pre-operative treatment therefore consists of placing the patient upon a moderate diet for twenty-four to forty-eight hours preceding the operation. Nothing else is necessary, and other processes are not only superfluous but inconvenient to the general practitioner. 
The operation is carried out in as simple a routine method as possible, keeping in mind at all times these three dangers, viz., casting accidents, prolapse of the bowels and infection.

Equipment.-The necessary equipment for the operation consists of the following: A casting outfit, scalpel, emasculator and ecraseur, operating sheets, green soap, tablets of bichloride of mercury, finger-nail brush, sterile, dry gauze packs in a sterile container, a trocar, a one-quart bottle, and a large needle and suturing material, preferably linen tape one-fourth inch broad.

Casting.- For the sake of uniformity of method all patients should be operated upon in the casting harness. The operating table offers no advantages and is not always at hand. The casting harness to use is the one that you are familiar with, providing you are skilled in its use and can adapt it to the operation. Properly confining the animal is a larger question than the actual operation, since upon it depends, not only one's success in satisfactorily performing the operation, but also the danger of casting accidents, and to a degree the dangers of prolapse of 
the bowels and of peritoneal infection. The requirements of such a harness are:

1. It must hold the animal firmly so that no change of position is possible.

2. All four legs and especially the hind legs must be fully flexed upon themselves and held so firmly that change of position is impossible.

3. The hind legs must be held by the harness in a widely abducted position with the legs so flexed that the hoof is just slightly in advance of the stifle.

I cannot emphasize too strongly the importance of this latter requirement. One should study and practice the art of casting until he is perfect in it; too many failures in surgical operations are the direct result of bunglesome and imperfect tying.

The operating sheets mentioned in the list of articles needed for the operation have served me very valuable purposes and saved me much time and annoyance during operation. They are merely muslin sheets one and one-half yards square, some of which have central oval openings seven inches long by one inch wide. 
Plan of Procedure.-The details of conducting an operation in the country are about as follows: Upon arriving at the place of operation a spot for casting is selected. There are no particular specifications regarding a casting site except that it be level and of sufficient size. A grass plot is best, although not indispensable. A clean operation can be done anywhere, but more care is required in dirty, dusty surroundings. When the casting site is selected, the owner is directed to procure a pail of warm water and a basin and to have the patient brought out. While this is being done the operator prepares his equipment for the operation. The scalpel, emasculator, ecraseur and needle, threaded with a piece of tape fifteen inches long, all previously sterilized by boiling, are laid out on a clean (if not sterile) towel on some improvised table, as a board, box or medicine case. The quart bottle is. filled with water and to it is added enough mercuric chloride tablets to make a solution of $1-1,000$ or even 1-500. The can of sterile gauze, the nail brush, soap and operating sheets are placed conveniently near. The horse is then cast and tied, the opera- 
tor (who, in country practice, must do the tying as a rule), wearing gloves to protect his hands to a certain degree from contamination. Chloroform is not used.

After the animal has been cast and properly tied for the operation, is the time to make the examination if a diagnosis of side is necessary. Of course, this is a question that needs attention only when one testicle has been removed and there is a scar on both sides of the scrotum. The side from which the testicle has been removed can be told in all cases by the presence of the stump of the cord or the spermatic fascia in the scrotum or inguinal canal of that side except in cases where the testicle removed was an abdominal testicle, when there will be no stump present. These cases are rarely met with, and a positive diagnosis of the side can be made only by abdominal exploration during, the operation. Ordinarily when one testicle is removed it is a descended testicle and its removal leaves a stump in the scrotum and inguinal canal that can be easily determined by careful examination. The history by the owner is usually of no value and 
the character of the scrotal scar means nothing. As the operation proceeds the operator further satisfies himself as to his diagnosis as will be mentioned hereafter.

A determination of the side having been made, the patient is placed in a position half way between a lateral and dorsal decubitus, with the operative field uppermost. This is usually best accomplished by placing the horse in a lateral position and then by means of a rope noose on the upper hock have an assistant apply a little traction as if to roll the patient over on its back. This not only places the patient in a good position but abducts the upper limb and improves the condition of the operative field and thus facilitates the operation.

Cleansing the Field of Operation.-The next question for the operator to concern himself with is that of the aseptic preparation of the operative field: An appreciative mind will understand that all the dangers of this, as well as any other surgical operation, are increased by prolonging the period of the operation. Consequently the period from the time the casting harness is put 
on the patient until the animal is again up and in its stall should be as short as is consistent with good surgical principles. The process of asepticizing the operative field is one in which much time can be saved by a study of the conditions. Excessive scrubbing and cleansing is not only without results of value but often productive of conditions exactly opposite to those at the production of which the process is aimed. Absolute asepsis can not be obtained in veterinary practice except at a great outlay of expense and trouble that is not justifiable. In cryptorchid operations relative asepsis is all that is needed for successful work. Peritoneal infection and scrotal infection are the least of my fears when operating. A good rule is to be as aseptic as the conditions will allow without endangering your patient by a prolonged, bunglesome technic (and without losing money on the operation).

The method that I follow in country work in preparing the operative field requires from two to five minutes, the length of time consumed depending on whether it is done by myself or by an assistant while I am scrubbing my hands. The 
process consists of scrubbing the scrotal area only, with green soap and water until it is free from visible dirt. The upper foot, leg and thigh are then encased in an operating sheet which is clean (not sterile) and which is applied in a few seconds of time, being made so as to fit the parts and supplied with proper means of attachments. This protects the field against serious contamination from that source. The lower leg may be covered in a like manner, but this is rarely necessary. The soap and water scrubbing is confined to a small area of the scrotum at the point where the incision is to be made. This is important. Uncleaned areas near the field of operation are covered by a sheet and are just as removed from the operation as if they were on another animal.

The soap and water scrubbing over, and the two hind legs encased in protective sheets, the operator proceeds to scrub his hands and arms, paying particular attention to the hand that is to be inserted into the belly wall. Relative asepsis only is aimed at by a one- to three-minute scrubbing of the hands with the brush and green soap, followed by a short scrub in the bichloride solu- 
tion. This being done, the operator with clean hands gives a short final scrub to the operative field which is then subjected to an application of the bichloride solution and an operative sheet spread over the belly and scrotal region so that the opening comes over the line where the incision is to be made. The area of the incision is then painted with tincture of iodine, a quick, practical and efficient means of producing surface asepsis.

The Incision.- The routes by which the abdominal cavity is entered by cryptorchid castrators may be clased into three general groups, viz.:

1. Through the inguinal canal.

2. Directly through the belly wall in the neighborhood of the internal ring.

3. Directly through the belly wall in the upper flank region.

There are a number of varieties of each group, each of the numerous operators varying the process to suit his individual taste.

The method that I prefer is the inguinal canal route. The technic of entering the abdominal 
cavity by this route is as follows: An incision, five or six inches long, is made through the scrotum parallel with and one or two inches from the median raphe. This incision is carried through the skin and dartos into the scrotal sac. When this is done the scalpel is laid aside and the remainder of the process is carried out entirely by blunt dissection with the fingers. The scrotum is found to contain considerable areolar fascia and a mass of blood and lymph vessels. No attention is paid to these; they are pulled this way or that, until an opening is made through them down to the external ring of the inguinal canal, which is but an oval slit through the aponeurosis of the external oblique muscle, large enough to freely to admit the operator's hand. This muscle is located just in front of the pubis and at the side of the prepubian tendon, landmarks that are easily determined. The exposure of this ring and the introduction of the hand into it is a matter of no difficulty. The fingers of both hands are used in the dissection up to this point. Now but one hand is required to finish the opening. 
Traversing the Inguinal Canal,- The operator places himself so that he is facing the field of operation and uses the right hand if it is the left testicle that is retained and vice versa. The hand used is inserted through the scrotal incision and through the external inguinal ring into the inguinal canal. The fingers of the hand should be bunched and directed toward the internal inguinal ring, to which they are gradually forced, separating the muscular belly of the internal oblique muscle, which lies on the palm or side of the hand, from the aponeurosis of the external oblique muscle and Poupart's ligament which lies on the back of the hand. While the introduction of the hand through the external ring and into the canal is always an easy matter, the passing of the hand up the canal in the proper direction and the locating of the internal ring is, to the uninitiated, usually attended with more or less difficulty. The direction to go is deep into the fold of the groin, keeping back against Poupart's ligament and the thigh muscles.

Most beginners, I have found, have trouble in locating the internal ring because of two chief 
mistakes. One is in keeping too far forward and the other is in being afraid to insert the hand far enough up the canal. I therefore try to emphasize the importance of going high up into the groin and keeping back against the thigh when forcing the hand up the canal.

Locating the Internal Inguinal Ring.After the canal has been traversed by the hand the selection of a spot for the opening into the belly is the next thing of importance. There are four places that may be used and are used by various operators.

1. Through the internal ring.

2. Below the internal ring.

3. In front of the internal ring.

4. Above the internal ring.

No matter what position is selected for the opening, the wise operator will first locate the internal inguinal ring as a starting point. This ring represents the upper end of the inguinal canal. After the hand has been forced up the canal to a point beyond the upper border of the internal oblique muscle the operator finds that only a relatively thin structure separates his 
fingers from the abdominal viscera, which can be felt more or less clearly. This thin membrane consists of two chief parts or layers. These are, first, the general fascial lining of the abdomen, which is often designated as the transversalis fascia and is spread out as a lining of the entire abdomen and pelvis, and, second, the peritoneum.

In the animal with the testicle undescended the internal ring is not an opening or a slit as it is sometimes said to be but it is merely a thinnedout area of the above mentioned transversalis fascia, this area being bordered and limited in front and below by an arched band of connective tissue which, after the descent of the testicle through the fascia at this point, forms the true ring. The upper and posterior borders of the thinned-out area of the fascia have no limiting band of fibers and, as a matter of fact, in the ridgling the area is not defined at all in these two directions. (The anatomical facts may be beautifully demonstrated by a dissection of a seven or eight-months' fetus.) Consequently, the operator, in searching for the internal ring, does not feel for a slit-like opening, but searches for a 
thin portion of the membrane which presents an arched, limiting band of fibers in front and below. This band may often be demonstrated externally by deep palpation in the middle of the fold of the groin. Its determination with the hand in the canal is a matter of little difficulty.

In a great many cryptorchids the testicle or epididymis has partially descended through this area and one may find a condition of affairs varying from a mere looseness of the fascia in the area to a finger-like projection of it containing the tail or more of the epididymis. Ofttimes the tail of the epididymis has descended through this area and the band of fibers, which normally contracts after natural descent of the testicle, has contracted down, constricting the testicular structures so that the globus minor of the testicle is below the band and the globus major and the body of the testicle is above and within the abdominal cavity and unable to descend further.

The internal ring, or better, this area in the transversalis fascia, lies just anterior to the shaft of the ilium at about its middle and the fascia just behind the ring is reflected backward into the 
pelvis where it becomes the pelvic fascia and where it is more or less firmly anchored. I, therefore, often consider the internal ring in the ridgling as being a thin area in the transversalis fascia bordered anteriorly and inferiorly by this arched band of fibers and posteriorly and superiorly by the shaft of the ilium, around which the fascia is reflected into the pelvis and to which it is more or less intimately attached. This area as defined is just about large enough to admit a hand with ease. The recognition and protection of the integrity of the borders of this internal ring is a matter of much importance in the operation.

In the process of passing the hand up the canal and in locating the internal ring, the operator may inform himself concerning a number of things. If it is a second operation he may observe by the scar tissue how far up the inguinal canal the previous operator went and where and whether or not he entered the abdominal cavity. If a diagnosis of side has been made, the operator while in the canal confirms it by the absence of the cord stump in the canal. One, of course, observes whether or not the testicle or any part of 
it has descended into the canal, producing a complete or partial flanker. If it is a complete fianker, all of the testicle having passed through the inner ring, the case is handled as a plain colt. If only a part of the testicle is descended, ignore the condition and operate as a ridgling, making the opening at the usual point. In the partially descended testicle it is almost always the tail of the epididymis that has descended and the ring has contracted down around it so that the testicle cannot pass through and usually cannot be pulled through with safety to the ring. I have found that these are best handled by passing up along the side of the descended tail and, making the opening at the usual place, pulling the descended portion back into the belly and out the opening.

Opening the Peritoneal Cavity.- I have satisfied myself that the best place to open into the peritoneal cavity from the upper end of the canal is at a point just in front of the shaft of the ilium, at the upper part of the internal inguinal ring. In operating, I locate the internal ring and then proceed upward and somewhat backward until I come to the point where the 
fascia passes back into the pelvis and here I thrust two fingers through into the belly cavity. In making the opening one must remember that there are two layers to go through, the fascia and the peritoneum. Sometimes the peritoneum pushes ahead of the fingers and strips off of the wall and requires a special effort to puncture. This is particularly true in older horses and in second operations where age and inflammation have thickened and toughened the peritoneum. It is also more apt to occur in the horses with empty intestinal tracts.

Before leaving the subject of the opening into the belly I wish to emphasize one thing. Preserve the integrity of the band of fibers that bounds the internal ring anteriorly and inferiorly. This band is not easily torn, but in the use of force in extracting the testicle or in other manipulations, see to it that no great tension is thrown upon it. So long as this band is intact the rent in the fascia is limited by it. If it is torn across, any increase in the intra-abdominal pressure may cause it to tear farther down and the protection against prolapse of the bowel is lost. In all cases where an 
enlargement of the opening is necessary make it upward and backward; never by use of the knife or other means enlarge the opening in the other directions. If one finds a testicle so large that it cannot be forced out through this area without endangering this band of fibers, then it is too large a testicle to be removed through the inguinal region. This is too dependent a portion of the belly wall for large openings at any point. My method of handling such cases, which fortunately are very rare, is, if the testicle cannot be forced through the opening after all means of reducing its size (tapping of cysts, etc.) have failed, to discontinue the operation at this point, allow the inguinal wound to heal, and after three or four weeks remove the testicle through a laparotomy in the upper flank region.

Locating the Testicle.-We will presume that the operator has traversed the inguinal canal, located the internal ring area, and advanced beyond this area in a direction upward and backward until he finds his fingers against the pelvic inlet at the middle of the shaft of the ilium, and at this point has thrust two fingers through the medium 
separating his hand from the peritoneal cavity. With the same movement by which the opening is made, it should be enlarged to a size sufficient to admit three fingers, by the spreading of the two fingers that have been used. If this is carried out quickly and if the rent made is held open by the two fingers and at the same time the hand is retracted somewhat so as to make an empty space in the upper end of the canal, the testicle or some part of its cord will be forced out into the palm of the hand. This will occur in a very large percentage of the cases, in all that are not complicated by adhesions or grossly pathological testicles.

This little process of "coaxing" the testicle out is possible only when the animal is properly tied, when the opening is properly located, when the abdomen is not too empty, and there is an intraabdominal pressure, and when the animal is not anesthetized. To the beginner, with some doubt as to his ability, there is no more pleasant sensation than that produced by the testicle forcing itself upon him and down the canal.

If the "coaxing" process fails in its purpose after a few seconds' trial, then the fingers explore 
the region inside the opening. The cord structures pass from above downward in close juxtaposition to the opening. They are attached to the belly wall near the opening and consequently cannot get far away. More often they are right beneath the finger tips, very often they are in front of the opening and less frequently they are behind the opening. In the past six years with a large series of cases it has not been necessary for me to introduce the entire hand into the abdomen to locate the testicular structures. I have, in several cases, introduced the hand into the abdomen for the purpose of examining pathological and enlarged testicles, and for overcoming certain conditions in the removal of testicles.

No Search Necessary.- With due attention to the entrance into the abdomen, search for the testicle is eliminated. It is right at the finger tips when they are introduced. The only thing that is necessary is to be able to recognize the difference, by sense of touch, between the testicular structures and loops of bowel. This should not be difficult, but I notice that some are unable to do it with certainty. Examination of the structures 
that present themselves to the fingers will soon reward the operator by a discovery of the cord or testicular parts. If in doubt, bring the structure down the canal and examine it by the sense of sight. Remember that some of the structures wanted are just inside the opening and that a little patience will reveal them.

The time-worn quack story about going up to the diaphragm and the spine to find the testicle is to be forgotten. It is for the edification of the laity only. I have never found it of value to use the gubernaculum as a guide in finding the testicle. Some parts of the epididymis, cord or testicle presents itself invariably upon entering the peritoneal cavity, and rarely indeed is the slightest search required.

Removal of the Testicle-The testicular structures having been located and recognized, they are brought down the canal and removed. This is usually an easy matter. The testicle and epididymis are drawn down by the fingers until an emasculator can be applied. It is well to have at hand an ecraseur to use in case the cord structures are so short that the testicle cannot be 
drawn far enough down to use the emasculator. One can use an ecraseur in all cases and dispense with the emasculator altogether, but I have found that an emasculator can be used in about ninety per cent of the cases and, being a much quicker and easier method than the other, one is justified in carrying both instruments in his equipment. In cutting off the testicle see that the three parts are removed, viz., body of the testicle, head of the epididymis and tail of the epididymis. These three parts are often far separated in a retained testicle and it is well to see that they are all included in the parts removed.

"Cutting ' $\mathrm{Em}$ Proud" a Fake.-I might say in this connection, that the old idea that leaving on the stump of the cord, a part of the epididymis would influence the nervous and physical development of the animal and give to it the characteristics of a stallion cannot be substantiated. The influence that the testicles have upon the physical and temperamental development of the animal depends upon an internal secretion elaborated by these organs, absorbed into the blood and lymph channels and exerting its influence, in 
harmonious relation to other internal secretions, upon the activity and metabolism of the various systems of organs. This internal secretion is elaborated largely if not entirely by groups of epithelial cells embedded in the stroma of the body of the testicle and not found in any part of the epididymis. I have satisfied myself on the proposition by leaving the epididymis in a few castrated animals with negative effect.

Complications That May Exist. - Occasionally more or less difficulty is met with in bringing the testicle through the opening and down the canal. When one has lockted the cord and moderate traction on it fails to bring the testicle into the canal it is due to one of the following causes:

1. An enlarged testicle, which hangs heavily over the border of the ring.

2. A partially descended testicle, the tail of which is gripped by the contracted ring (this, of course, should have been recognized previously).

3. Adhesions of the testicle to the abdominal wall at some point.

In the presence of any of these complications the first thing to do is to examine and diagnose 
the complicating conditions. The cord which has been grasped and pulled down into the canal is held by the fingers of the free hand or by a pair of heavy forceps. The hand in the canal is then passed up along the cord and with the fingers, or if need be the entire hand, in the peritoneal cavity the structures are examined, remembering that the testicle is attached to the lower end of the doubled cord in the inguinal canal and that by following this out the testicle will be reached. Occasionally it may be best to turn the cord loose, especially if the entire hand is inserted into the abdomen. Cases of these kinds are fortunately rare and when one is met a little patience on the part of the operator will allow him to make a positive diagnosis of the complicating condition.

The treatment of adherent testicles is obvious. The adhesions are broken up and the testicle brought down. In the cases in which the tail of the epididymis has descended through the internal ring and is in the grasp of the ring the treatment consists in pulling it back into the belly and out through the opening and down the canal. The handling of enlarged testicles is a subject of more 
importance. From a practical standpoint the enlarged testicles may be divided into two classes, viz., cystic and solid, the former admitting of a reduction in size by tapping. Upon the discovery of an enlarged testicle during the progress of the operation the operator settles two questions in his mind. First, is the testicle small enough to pass out through the ring safely? This, however, varies greatly in different cases and the operator is the judge of the possibilities in a given case. Second, is the testicle cystic? If so, it is tapped through the inguinal canal with a long trocar.

The technic is as follows: An assistant, not necessarily but best a skilled assistant, empties the rectum of the patient and inserts the hand into the same as far forward as possible. By the directions and assistance of the operator, the assistant, by rectal manipulation, pushes the testicle up against the internal ring and holds it there firmly by pressure from behind. The operator then inserts a trocar up the canal, and it is usually an easy matter to draw off the cystic fluid. The rectal manipulation of an assistant is of great value also in the withdrawal of a large testicle 
through the internal ring. Where the mass is so large that there is difficulty and danger in pulling it through the ring by traction on the cord alone, then an assistant working through the rectum can be of great assistance. He can force the testicle through the ring in a manner that is much safer than that of pulling it through and much larger testicles can be removed safely by such means than can be removed by pulling alone.

Laparotomy May Be Necessary.-If the examination or repeated trials demonstrates the fact that the testicle is too large to be safely removed through the inguinal canal and its size cannot be reduced by tapping or other means, then there is but one thing to do. Discontinue the attempts at removal, dress the wound, allow the patient to rise, and wait a couple of weeks until the inguinal wound is healed and then take the testicle out through a laparotomy opening in the upper flank. One might argue at this point that a rectal exploration preceding the attempted operation would have made unnecessary the exposure of the patient to the dangers attending the $e^{\pi}$ abdominal exploration, but this is not true. I have yet 
to see the man who is positive enough in his findings by rectal examination to gamble on his diagnosis. Abdominal exploration is certain in its results and the dangers are practically nil when one practices good technic.

The tapping of cystic testicles is not attended by any danger. The contents of these cysts is sterile and leakage into the peritoneal cavity is of no consequence. I remember of but one report in the literature of an infected testicular cyst. They are so rare as to be of negligible import.

Wound Treatment-After the testicle has been disposed of. The dressing of the wound is to be undertaken. This is simple. It is best explained by emphasizing a few things that it is important not to do.

Do not, at any time, introduce any kind of antiseptic or aseptic fluids into the inguinal canal. From the time the operator takes his scalpel to make the scrotal incision until the operation is completed, clean methods are important, but antiseptic solutions within the abdomen are tabooed.

Do not at the end of the operation remove the blood from the wound. There is no hemorrhage 
of any consequence and it is seldom that one needs to ligate a bleeding point. The only hemorrhage that one can have is from the vessels of the dartos and they are small. Hemorrhages from the stump of the cord is practically unimportant except occasionally in pathological testes, in which case one can ligate before cutting off with the crushing instruments.

Do not introduce a pack of any size into the inguinal canal. I believe that any operation that requires the canal to be packed is, generally speaking, a failure. Operating by the foregoing method, heeding the warnings that have been given, one will never have need for the pack.

The opening into the belly that is described in the foregoing is a self-protecting one against escape of the viscera. Of course, it is possible for a loop of bowel to come down, but I have never had such to occur. A dressing of the wound that is to be recommended is as follows:

As soon as the testicle is disposed of a small pack of dry sterile gauze is placed in the scrotum and the scrotal wound is sutured by a continuous suture of the linen tape. Its chief purpose is to 
absorb by capillarity, the juices collecting in the wound and when removed, twenty-four hours later, to leave an open, well-drained wound. In suturing the wound it is well to leave the ends of the sutures long so that they hang down a distance of four or five inches. This facilitates their removal. The owner or caretaker of the patient, if in country work, is shown how the stitches are put in and how and when to remove them.

Accidents Subsequent to Operation.- The release of the patient from the casting harness should be conducted with care. The period of release and until patient gains his feet, if attended by struggling, is a time when intestines may be forced down into the canal. Consequently this is to be considered one of the danger periods. The ropes must be removed with dispatch and removed quietly so as not to excite the patient. When untied the patient is given assistance in arising so that awkward movements, as wide abduction of the hind limbs, will not occur to open up the canal and tempt intestinal protrusion. I believe that the only danger of intestinal prolapse with the above operation is when the animal, carelessly 
forced to arise by the operator, awkwardly staggers about with the hind limbs widely apart and the belly muscles tensely contracted in its attempt to gain a balance. Therefore, care at this time is important.

If the intestines should prolapse at this time (a thing which I have not seen with this operation, but have experienced in using other methods), the scrotal pack and sutures will protect against all dangerous conditions until they can be returned. With the internal ring intact, as soon as the animal is squarely on its feet there will be a tendency for the intestines to return to the belly. This may be assisted if necessary in two ways. One can use a little pressure upward on the inguinal region or he can insert the hand into the rectum and by sweeping it across the region of the internal ring, pull the intestines back into the belly.

After-Care.- The after treatment of the patient is simple. As soon as he is released he is given a little water and is tied in a comfortable place and in such a manner that he cannot lie down. He is allowed a moderate ration of food 
and is kept quiet for twenty-four hours. At the end of this time, in the uncomplicated cases, the caretaker removes the sutures and pack after which the patient is treated as he would be had he been a straight colt. $\mathrm{He}$ is allowed to run at large or is given plenty of exercise and a full diet. I have never found irrigation or other treatment of the wound necessary. He is kept standing only twenty-four hours.

In Conclusion.- We may say the uncomplicated case requires but a short time for castration and is but little affected by it. These cases will feed immediately upon being tied in their stalls and there are no post-operative complications of any sort to deal with. Swellings of the scrotum and prepuce is usually less in evidence than in straight colts as the pack produces a better draining wound. Peritonitis is an evidence of inexcusable errors and carelessness in operating.

Double cryptorchids are quite frequently met with. They are handled as the single ones. Removal of the two testicles through a single opening is rarely advisable. Remembering that practically all cryptorchid testicles may be removed 
with but one or two fingers inserted into the peritoneal cavity, one can see that the opening up of the second inguinal canal would be far less injurious than inserting the whole hand through the belly wall in the attempt to bring across the second testicle. It is best to make a double operation, but remove both testicles at one casting. *

The operation where entrance to the perituneal cavity is made by an incision directly through the belly wall in the neighborhood of the internal ring is used by several operators and with success. I have not found it as satisfactory, from a number of standpoints, as the inguinal-canal route.

An operation that one will very infrequently have occasion to use is that in which the peritoneal cavity is reached through its triangle of the upper flank. This operation is the one of election when a large testicle is to be removed. The opening is made at a point where it can be completely controlled from a surgical standpoint, it can be closed and protected and it is where danger of intestinal prolapse is absent. Opening the belly cavity in this region is a safe procedure under even moderate aseptic conditions. I have 
had occasion to use it in cryptorchids and have repeatedly used it in spaying mares. The timehonored pronunciamento, that it is fatal to open the abdominal cavity of the horse, belongs to the pre-Listerian era and has little bearing on modern aseptic surgery. Successful laparotomy in the equine depends merely upon controlling the concomitant infection of the peritoneum, aside from which, it presents no serious difficulty.

Young patients are much more satisfactory to operate upon than older ones. One should, in studying the operation, select untouched yearlings or two-year-olds for his first patients, the yearlings being preferable to the two-year-olds.

Complicating conditions in young patients are exceedingly rare; in older ones they are much more common. Adhesions, hyperplastic and cystic testicles and the partially descended and strangulated testicles are all results of age. Older animals are more difficult to confine properly and being more liable to present complicating conditions are more apt to suffer from the accidents of the operation. 
To the beginner I would recommend that he select a young patient, and before operating carefully map out his plan of procedure. Nothing counts like system and nothing succeeds like the uniformly systematic man. 


\section{Cryptorchidectomy in Horses"}

By C. E. Steel, D. V. S., Oklahoma City, Oklahoma

Comparatively few of us have the opportunity to castrate cryptorchids often enough to become really proficient in this operation and yet it is one that, with a knowledge of the anatomy of the part concerned in the operation and with modern surgical antiseptic and aseptic measures at our command, the average practitioner should not "side-step" in favor of the so-called specialist, who often is anything but clean and scientific in such work.

As Dr. L. A. Merillat has said: "It is indeed remarkable how one can mutilate a ridgling with impunity in the frantic search for a well hidden testicle, if the parts are not infected in the effort." Most of us know of one or more empirics who are successful ridgling operators in spite of their uncleanly methods and utter ignorance of asepsis

*Reprinted from Missouri Valley Veterinary Bulletin, January, 1910. 
and antisepsis. When we compare our own efforts with such men, we are somewhat inclined to lose faith in the value of antiseptic precautions and to lose confidence in ourselves.

From long practice, professional ridgling castrators become expert and the time required to perform the operation with them, usually amounts to but a few seconds or minutes after the animal is secured. With the hands of the skillful though unscientific operator ordinarily clean, the peritoneum is far less likely to become contaminated than with the inexperienced operator, who usually employs some half-way measures toward securing asepsis and frequently hunts for the testicle for an hour, or more, and sometimes even then fails to find it, much to his own embarrassment and humiliation. The obvious deduction is supplant lack of experience by the strictest precautionary measures at our hands. In fact, however skilled one becomes he should most religiously follow the technic of preparing the operative field, instruments and hands, as though he expected to search indefinitely for the hidden testicle. 
The following is about the routine which I have employed and, I may say considering the number it has been my lot to operate upon during the past few years, and the results attained, it seems to be a practical method.

I first apply a twitch to the nose, lightly, and make an inguinal examination with the animal in the standing position. In some horses in good condition, particularly those over two years old, the superficial inguinal lymphatic glands may deceive one, especially in nervous or ticklish animals, in which squeezing these glands may cause them to flinch, much as would pressure upon the testicle itself. The importance of this preliminary step is considerable in some cases, as many owners of ridglings are not willing to assume the risk incidental to the operation, and the veterinarian's sense of touch is called upon to decide whether the horse is an abdominal ridgling or -merely a "high flanker." In exceptional cases it may be necessary to caste the animal to make a correct diagnosis, but in horses thin in flesh it is an easy matter to determine whether they are ridglings. 
The animal is prepared for the operation by withholding feed and perhaps water for a period of twenty-four hours, depending somewhat on his condition; this is not always advisable, as circumstances may make it inconvenient or impossible. For casting select a grassy spot away from manure heaps and other insanitary conditions usually met with around stables, and tie up the tail securely. With a modified Conkey throwing harness and a hood to protect the eyes of the patient cast and tie him. I do this myself with the aid of one man at the head and another with one of the side-ropes. But it is preferable to have an experienced assistant to do the handling of harness and ropes, and tie up feet with damp cloths. Having previously scrubbed my hands with a brush and thoroughly cleansed nails with water and soap and rinsed well in a 1-3,000 bichloride solution, have an emasculator, ecraseur, curved needles, sterilized silk, arteryforceps, and convex bistoury, or regulation castration knife at hand in one per cent chinosol solution in a clean pan. I have also a kettle of boiled water, cooled to luke-warm temperature, a 
clean pan, a cake of soap and clean towels ready for use and after having an assistant wet down the entire abdomen to allay fiying hairs and dust, $I$ have the scrotum and inguinal region scrubbed well with soap and water, containing any reliable antiseptic, then thoroughly rinsed with bichloride solution, 1-3,000 strength. If I have had to assist in the castrating (with gloved hands, of course) I proceed to wash my hands and wrists in same strength solution, and with twitch applied to the patient's nose, make a four or fiveinch incision about one inch from the median line. I prefer the side on which I am operating, uppermost. In making the incision I try not to go deeply, and thus avoid wounding the large scrotal veins that may lie in such a tortuous network that it is hard to keep from cutting them if the knife goes deep. If, however, any of the larger blood vessels are severed, it is not a difficult matter to take up with artery-forceps and ligate, a thing it is advisable to do at once.

If the animal has not been operated upon before, it is an easy matter to break or tear down the fascia in an outward and forward direction 
for a distance of from six to ten inches, depending upon size and condition of animal. If, however, he has been tampered with, the cicatrical tissue may offer considerable resistance. One should use judgment though, and be sure to break down sufficient tissue to insure plenty of working room for the hand, so as not to tire it in succeeding steps of the operation.

Having penetrated to the above-named distance, one should be in the neighborhood of the internal inguinal ring, which is recognized by a much thinner feeling than the surrounding parts. A rotary motion of the hand will aid in reaching the part, and some operators employ sterilized or antiseptized oil to facilitate the process. I have never used oil. When my fingers have reached the peritoneum covering the internal inguinal ring $I$ instruct the man at the head to tighten the twitch, and at the instant of full inspiration I perforate it with either index or second finger or both, and usually contact the testicle immediately. In many cases, however, I have had to search or finger for the organ or the vas deferens for varying lengths of time, but in no case have 
I found it necessary to insert more than two fingers into the abdominal cavity excepting where a cystic formation or other abnormality was present.

The fecal matter in the floating colon is not to be mistaken for the testicle, being easily distinguished by its softer consistency. Mesenteric arteries should be easily recognized by their distinct pulsations and not mistaken for the vas deferens. A flabby, undeveloped testicle and epididymis, however, closely resemble in touch the small intestine. In a number of cases $I$ have withdrawn the small bowel to the outside sufficiently to recognize it, without bad after-effects. An assistant with the ability to recognize a testicle through the rectal wall, can sometimes render valuable aid in locating the missing organ and the operator should resort to it himself with his disengaged hand and arm, rather than keep the animal down unnecessarily long; prompt and careful cleansing of the hand and arm by an assistant before the instrument or the operating field is touched during the remainder of the 
operation will usually avoid infection from the procedure.

When the testicle has been located and brought into view it is removed either with an emasculator or an ecraseur and the opening into the abdominal cavity carefully examined to determine the size of the peritoneal opening and make absolutely sure that no bowel protrudes. If, by any mischance, a larger opening has been made than one feels safe in leaving, even when no intestines have escaped, I prefer to pack carefully the entire wound and stitch the packing in with a continuous suture. In ordinary cases, such packing is not necessary.

In releasing the animal, I prefer to have him stand quietly for from six to twelve hours. If he has been packed, instruct the owner how to remove the gauze, and have him turned to grass, or exercised sufficiently to overcome soreness. Should swelling occur around the scrotal wound, insist strenuously on exercise, first, last and every time. If peritonitis develops after such an operation as described, the animal is doomed to die, in nearly all cases, in spite of treatment. 


\section{An Interesting Monorchid*}

By Frederick Hobday, F. R. C. V. S., London, England

This, a two-year old chestnut cart-horse, belonging for Mr. T. Stainton, M.R.C.V.S., was of especial interest as it proved to be a true monorchid. There was no evidence or history of any prior attempt at castration; in fact, it was known with certainty that no testicle had ever been removed. The left one was present in the scrotum and was removed without any trouble. On the right side the abdomen was penetrated in the usual situation, close to the inguinal ring, and a careful search revealed not only the absence of testicle, but a gradual merging of the end of a rudimentary cord into the lining of the peritoneum of the pelvis. After making sure of this by tracing it repeatedly, the hand was withdrawn and the inguinal canal carefully closed by sutures.

*Reprinted from the American Journal of Veterinary Mediaine, October, 1910. 
The colt was allowed to come out of his anesthes1a and he got up apparently none the worse for his experience. This was about 5 o'clock. At $10: 15 \mathrm{p}$. $\mathrm{m}$. the animal was heard to be making a noise in the box as if in violent pain, and upon examination the bowels were found to have descended. The weight had ruptured one of the sutures and a loop of bowel had come down nearly as far as the hocks.

Assistance was summoned, and after considerable difficulty the colt was cast and the bowel returned. As much washing and disinfecting was done as was possible under the circumstances, and a plug of cotton wool was inserted. This was inserted underneath a row of sutures, and then followed by a second row of sutures, in such a way that the pad could be changed without danger of allowing the bowel to escape, the first layer of sutures not being touched or interfered with in any way.

On the following morning the colt's temperature was $103^{\circ} \mathrm{F}$., and during the subsequent days it varied between $102^{\circ}$ and $103^{\circ} \mathrm{F}$. The pad of cotton wool was changed on numerous occasions, 
and febrifuges, tonics, or stimulants were administered internally at discretion. Anti-streptococcic serum was also given.

Peritonitis was evidently present, and in spite of all efforts death eventually took place a month after the operation.

An autopsy at which Dr. Kendall, D. V. S., M. R. C. V. S., and Mr. Benson, M. R. C. V. S., in addition to Mr. Stainton and myself were also present, confirmed the absence of any testicle on the right side, nor was there any evidence of such an organ ever. having existed, the spermatic cord being clearly traceable and merging imperceptibly into the peritoneum of the pelvis. Such cases are rare, and are worth recording. I have already reported a similar case in my little brochure upon "Cryptorchid Castration," and a further still more curious point in which both testicles were absent.

The remainder of the autopsy was of interest only in connection with the peritonitis. The loop of bowel which had descended was matted together, and there was a long abscess between the two portions of the loop. This contained a piece of dirty straw which must have been overlooked, 
as it quite readily might have been, when the bowels were washed and returned.

On the left side the end of the cord from which the testicle had been removed could be found quite easily, and had nothing about it upon which to make any comment. 


\title{
A Castrator's Error*
}

\author{
J. L. Perry, M. R. C. V. S., Cardiff, Wales
}

I received a letter asking me to attend a cart horse, aged three, upon which an attempt at castration had been made by an unqualified man three days previously.

The owner said in his letter: "The castrator, a man who does all that kind of work about here and has hitherto been most successful, 'bunched' up something in the clam. I saw at once it was not a testicle, and told him so. He insisted that the colt was malformed and that it was the other testicle all right. I, however, left in disgust, and learned afterwards that he had at once proceeded to sear through this 'something' with the hot iron, immediately this was completed about twelve inches of penis fell from the horse's sheath to the ground." So he had amputated the penis in mistake for a testicle! He then found and removed

\footnotetext{
*Reprinted from American Journal of Veterinary Medicine, May; 1911.
} 
the other testicle. The horse was now very weak and ate but little, his sheath was a tremendous size, like a sack of potatoes.

Mr. C. E. Smith, M. R. C. V. S., saw the horse in my stead. He found the sheath almost justified the description given it by the owner of the horse. It was engorged and pointing in places with infiltrated urine. After casting the animal and well lubricating the inside of the sheath with vaseline, he discovered, after a lot of tedious manipulation, the mutilated end of the penis about a foot away from the natural opening of the sheath. The swelling being so severe, the urine could only come away in a small dribble, so he decided to make an opening for the penis stump to come through the sheath in a position close to the proper castration wounds. The urethra protruded about one-eighth inch, but it was impossible to get a skin attachment for it; so it was left as it was with the intention of completing this part of the operation later on when the swelling had subsided. Punctures were made in various parts of the sheath to allow the urine which had infiltrated into the surrounding tissues to drain 
away. All the parts were thoroughly cleansed with warm antiseptics and dressed with carbolized vaseline.

I saw the case myself ten days afterwards. The sheath was slightly swollen; horse eating and improving in condition. Standing behind him and pulling the tail aside I could see about four inches of penis hanging through a wound in the sheath, and in position just where a mare's teats would be. The penis pointed downwards and backwards, and when urination took place there was a stream about the calibre of a clinical thermometer case directed upon the points of the hocks. The urethral opening was clearly diminished in lumen, and I told the owner that the horse should be cast again, and a further small portion of the penis removed so that the urethra could be properly everted and stitched back to avoid further stricture. This he would not consent to, preferring to "wait and see" how the horse went on.

I was not asked to attend the horse again, but being in the locality a month or two afterwards saw him at grass. Both hocks were then in a 
terrible mess, due to the constant dribbling of urine upon them. The urethral opening was evidently very small, as one could see the urine coming away from the penis in a very fine spray. Owner still refused surgical interference. I wrote him about twelve months ago on another matter, and asked him how "Farmer" was going on, expecting to hear he had been sent to the kennels. His reply was, "The horse is working on the farm regularly, and except for requiring an occasional drench does all right."

I might add that I tried at the time to persuade the owner to institute proceedings against the castrator, either for cruelty or in a civil court, but this he would not do, the reason being, as I learned afterwards, that he had arranged terms for the castrator to pay him the sum of $\$ 125$ in instalments, as damages. This would, of course, account for his desire to avoid further expense or publicity. He wanted the matter kept quiet till the money was paid; hence also his employing me in lieu of other veterinarians nearer his home. 


\section{Hemorrhage After Castration*}

By Wirt R. Barnard, D. V. S., Belleville, Kansas

I was called to see a two-year-old colt castrated nine hours previously by a non-graduate practitioner. The owner had stopped the hemorrhage, but I found the colt very weak and staggering, pulse imperceptible, respiration abdominal and hurried. I administered one dram of nux vomica and in thirty minutes noticed great improvement.

The next morning, the owner telephoned the colt was down, unable to rise, and acting crazy. I made the call and gave nine pints of normal saline solution intraperitoneally. The colt ate and drank well, but after attempting to rise showed cerebral disturbance. I left a mixture of nux vomica, belladonna, digitalin and ferric chloride to be given in full doses every two hours.

\footnotetext{
*Reprinted from the Missouri Valley Véterinary Bulletin, May, 1908
} 
In addition to this the colt was fed one-half gallon of fresh milk, one-half dozen eggs and onefourth pound of sugar, well-mixed, twice daily, and all the hay and grain he wanted. After three and one-half days he got up on his own accord and has been doing well ever since. I noticed a decided change for the better after giving the saline injection and had not the distance from my office been so great I would have given a second injection.

At another time I was called to see a two-yearold mule that was bleeding badly, a result of castration by an empiric. I checked the hemorrhage externally, but the colt died twelve hours later from internal hemorrhage. I was called to this case in the night and the weather was so disagreeable and the lack of conveniences such, that I did not throw this colt and secure and ligate the artery-the only proper procedure. The animal died in spite of all medication though I now believe that full physiological doses of atropine hypodermically would have checked this as it will most other internal hemorrhage. 


\section{Castration of Pigs Having Scrotal Hernia}

By D. M. Campbell, D. V. S., Chicago

Cases of scrotal hernia in pigs or a rupture as the farmer calls it is a markedly hereditary condition. On some farms from year to year there are numerous cases of this kind among the pigs; on other farms this condition is scarcely known, its presence or absence depending, as may easily be demonstrated, upon heredity.

Some farmers castrate these pigs as readily as they castrate their ordinary boar pigs, but a great many others find the operation difficult or are entirely unable to perform it and with them such pigs are usually destroyed as soon as the hernia is noted or the condition is allowed to grow worse until death results from strangulation of the intestine or from a traumatism to the scrotum. 
The value of the animal is so slight that unless there is a considerable number of these "ruptured" pigs in the same brood or there be a very large number of hogs raised upon the place, this work can never amount to much from the veterinarian's point of view, but frequently when he is called to a farm for other work he is asked to castrate one or two or three of these pigs.

There is scarcely an operation that is more simple than this one and yet it is one with which some veterinarians have experienced a great deal of difficulty, because of faulty technic. To throw the animal, hold him on his side and attempt to castrate him, as is done in ordinary castration is to bring on such forcible extrusion of the intestines that no operator can successfully accomplish the castration, but if the pig be held up by his hind legs with his back to the holder and with his forefeet just touching the ground and possibly his neck between the ankles of the man holding him the intestines will of their own accord, or can readily be made to, return to the abdominal cavity and while held in this position castration is an exceedingly simple operation. 
Observe the usual aseptic precautions advisable in all minor surgery. If the inguinal aperture in the abdominal wall is very large it may be necessary to hold the testicle through the scrotum while the intestines are manipulated to prevent its return into the abdominal cavity along with the intestines, in which case the animal would have to be lowered before the testicle would again return to the scrotum, thus causing annoyance and repetition of the manipulation of the intestines.

Holding the testicle between the thumb and fingers as for ordinary castration cut through the skin and dartos as for the covered operation. Strip the cellular tissue from the tunica vaginalis as close up to the internal inguinal ring as it is possible to get. Then place a ligature very tightly around the tunica vaginalis or sac including the cord, vas deferens, the arteries, veins and nerves, first making certain no portion of the intestine is included in the ligature and that it is close enough to the internal inguinal ring to prevent subsequent saculation and a further escape of the intestine from the abdominal cavity. The ligation may be made with any stout cord, that has been 
rendered aseptic and the ends of it should be left long enough to hang slightly out of the scrotal wound. Cut off the cord with its covering membrane just back of the ligation. It is a serious mistake to incise the tunica vaginalis before the cord is ligated. Remove the other testicle and the operation is complete.

The peritoneal surfaces of the tunica vaginalis will adhere in a few hours and in two or three days the portion of the tunic below the ligation will slough off and come away together with the string with which it is tied. It is necessary to make the wound rather low so that drainage may be free. The entire operation requires less than one-half the time it takes to describe it and the mortality is practically nil.

It may be beneath the dignity of some veterinarians to charge a fee for this operation but the operation is not too insignificant to be appreciated by the owner and it is well worth while viewed from any angle. If undertaken at all of course it should be well done. 


\title{
Operation on a Hermaphrodite*
}

\author{
By 0. D. Chedester, D. V. S., Cordell, Oklahoma
}

Hermaphrodism is a condition in which there is a combination in a single individual of both male and female generative organs. In some cases, the individual possesses only one set of internal genitals, but both male and female external genitals. In others the internal genitals of both sexes are present. The former class is the more common and to it the case described below probably belonged. Hermaphrodites which simulate the male more nearly than the female are of much more frequent occurrence than are those which most nearly resemble the female.

A client of mine possessed a small, four-yearold, bay, hermaphrodite horse, weighing less than 900 pounds. The head, neck and shoulders of

\footnotetext{
*Reprinted from the American Journal of Veterinary Medicine, March, 1912.
} 
this animal resembled a stallion. The posterior half of the body with its perfect udder, resembled a mare. Its disposition was that of a stallion. The short penis, about three inches long, in an almost continuous state of erection, extended through a small opening six inches below the anus. Through this penis the urine was passed, usually dropping on the tail, legs and buggy wheels though it sometimes reached the dashboard, making it disgusting as well as embarrassing to drive the animal.

The faults of this critter were many. It could not be safely turned out with other horses or even into a pasture adjoining one in which other horses were kept. It could not be worked with other horses with any satisfaction. Every equine looked to it like a mare in estrum. With half an opportunity it would mount as for copulation and with the aid of its tail pressed against the erected penis would discharge the semen in its own tail. This young animal, though quite a curiosity, was worthless for practical purposes. The case, however, offered a fine opportunity for 
some experimental operating on my part, and as the owner agreed to it, the experiment was made.

This animal was cast and chloroformed; the tail bandaged and the operative field cleansed. A sterile soft catheter was introduced and the bladder and the urethra irrigated with an antiseptic solution. The penis was dissected one and one-half inches inward and upward and amputated, leaving the urethra protruding one-fourth of an inch. The catheter was left in situ and the bladder and urethra irrigated daily with a five per cent potassium permanganate solution for one week. The wound was given a daily dry dressing.

Owing to the position and irregular size of the urethra the amputation was much more difficult than this operation is ordinarily. Two weeks later a second operation was performed by laying open the urethra for a distance of three inches, thus for urinary purposes replacing a vulva. The wound was packed and the edges allowed to heal without uniting. From this opening the urine is now expelled as expeditiously as it is from the urethra of a mare. 
The patient was given the following treatment:

Nucleinic acid (yeast)

Sodium chloride

Sodium bicarbonate

Phenol

Aqua destillata grs. xii

grs. vi

grs. $\mathrm{V}$

m. ii

oz. i

Mix, filter and give hypodermically one dram twice daily in an equal quantity of normal saline solution. In one week the animal was well and ready for work and medication was discontinued.

As the testicles, if developed, were in the abdominal cavity, their removal was planned for a third operation, but never attempted because not necessitated by the changed disposition of the animal which strangely enough from the first operation became docile and began to grow and fatten until now it weighs more than 1,300 pounds. It can be turned loose or worked with other horses with satisfaction, and is a beast of burden equal to a mule. How are we to explain the loss of sexual desire without the removal of either testicles or ovaries? 


\section{Spaying Heifers on Western Ranches*}

By A. W. Whitehouse, D. V. S., Boulder, Colorado

Calls for this work on the part of the cowmen are not at all regular, and depend on three factors: the demand for breeding she-stock, the price at market points on fat open-cows and heifers, and the amount of available grazing. Perhaps the most important of these is the price of fat open-cows. When, as at present, these sell within a dollar or a dollar and a quarter of steers of similar breeding, very little spaying will be done. There is now no discrimination at market points against spayed heifers as such, and they sell on their merits at a price fully equal to steers in similar condition. This is as it should be, for they certainly dress out as well as steers, and sometimes better.

*Reprinted from the American Journal of Veterinary Medicine, April, 1911. 
One big outfit for which I have worked, from an annual brand of about 2,000 calves of both sexes, "cuts" the poorer half of the heifers for spaying each year, and this bunch, though it contains all the odd colors and ill-shapen calves, is said to make them more money than the open heifers or the steers. Spayed heifers are quieter than steers, and though they will not quite come to the same weight, they will ripen more quickly, and on very much less feed.

In discussing spaying with an owner who is contemplating it for the first time, it is well to advise him to be prepared to carry the heifers over at least two seasons, as it requires that length of time for the complete unsexing of the carcass and to derive the full benefit of the operation.

While the median-line operation is easier and quicker, and the immediate loss, providing the stitching is quite perfect, should be no greater, yet there are good reasons for preferring the flank operation. One of my clients has had a good opportunity to compare their merits, and I 
have been able to confirm his observations. Having 400 flank-spayed yearlings of his own breeding, he purchased 800 median-line spayed yearlings from a neighbor, the operations having been performed within six weeks of each other. Among the flank spayed yearlings were a very few rather persistent stitch abscesses (in a harmless place) which eventually disappeared. Among those operated upon through the median line there were a number of hernial sacs, and more having a (supposedly peritoneal) fistula which discharged a fluid usually clear. These did not fatten, and some few died, a year to eighteen months later.

This is my technic for the flank operation:

Preparation.-Just preceding the spaying, thirty-six hours of starvation is desirable but not often obtainable on the range from lack of suitable corrals. The animals should be watered the night before the operation or they get too "proddy."

Restraint. - I have never tried the chute and should suppose it slow. It is desirable to jam a lot of them in a small corral for roping and 
"snake" them out into a big corral of at least an acre for the operation. If the operating corral is small the spayed heifers are always charging the operator. We usually rope them by the head and the hind feet and stretch them. The upper or left-forefoot goes into the neck noose and a figure of eight is put on just above the hind fetlocks. The adjustment of this requires a good man on the tail. It is best to have a man sit on the head with the forefoot pulled over with a handle noose. It is hard, however, to get the boys to do this as they prefer to stretch them between two horses. This brings the abdomen too tight, and after breaking through it is often necessary to ask the man on the hind rope to slacken, so that occasionally the heifers kick loose from the figure eight knot.

Field of Operation.- Have the left side uppermost in the recumbent position; stand at the loin and rump and not at the abdomen. Grasp all of the flank you can get into the left hand and tense the skin. About two inches from the heel of the hand begin the incision and cut straight towards you-make it plenty long enough for easy work. 
I never clip or shave the hair from the field of operation, considering that there isn't time to do a good job and I am more likely to introduce clipped hair than loose hair, though I often find a little of the latter in my hand. I swab the field very freely with a two per cent solution of zenoleum or some of the coal-tar disinfectants.

The incision will be very little if any forward of the point of the ilium and will be surprisingly low down when they get up. Here the external oblique muscle is aponeurotic. I make an incision parallel with the fibres about one inch long and enlarge with the index finger of each hand. I then force my right hand cone-shaped into the incision and as soon as I feel the peritoneum, jerk in my hand so as not to separate it from the wall.

Equipment.-I wear blue overalls and a jumper, a clean suit each morning; have my shirt sleeves rolled up but the jumper sleeves hanging loose for a protection from the sun.

For the skin and aponeurotic incision I buy old razors and carry four with me. The blade is ground away so that there is only about one inch 
of it left at the end and a cutting edge put on the heel. I have a scalpel in my pocket but seldom use it. The other instrument is a pair of curved serrated shears six and one-fourth inches long such as some use for spaying bitches. I have a pair of long spaying shears (serrated) and a spaying emasculator but never use them.

At the fence I have several pans, etc., and the instruments go into a five-percent carbolic acid solution when not in use. One pocket of my jumpers I keep soaked in five percent carbolic acid and carry the instruments in it. I wash as often as possible in surgeon's boric-acid soap and water, but I cannot stand antiseptics in it for more than half a day's work.

Removal of Ovaries.-After breaking in, as - described, I turn the fingers toward the pelvis keeping the peritoneal wall in touch and with the back of the hand push back a fold of intentine. The left ovary should lie close at hand. I grasp it and bring it to the surface and with an instrument, razor, scalpel, or scissors shred the broad ligament till the ovary lies passive, but attached, in the left hand. Possibly dipping the right arm 
in the swab bucket I reintroduce it and follow the broad ligament to get the right ovary. Sometimes the tension has brought this within two inches of the surface and sometimes it is very hard to find (the weak point of the recumbent operation). I break down the broad ligament by passing the fingers through it and gradually bring it to the surface. This breaking through the broad ligament is very wearing on the skin of the fingers, soaked as it is, and the ligament cuts nearly to the bone on the first and fourth fingers near the distal joint. If the ligament is tough it needs shredding with the scalpel held in the left hand; it is rather risky to transfer the ovary to the left as it snaps back if the heifer struggles. Most of them, however, come out on a shred. I never introduce an instrument into the cavity, feeling that in rough, hasty, routine work there is danger in so doing. Finally I shred the ovaries off, using an instrument if necessary.

Sutures.-One in the aponeurosis of the external oblique and two in the skin-all three interrupted. I use common string cut in suitable lengths, soaking it all day in a strong coal tar 
dip, ten percent solution. An assistant does this work. He dips his hands frequently in an antiseptic solution. Most of the heifers go to market, but one of my clients has butchered a few and he tells me that there is an adhesion of skin and deeper structures at the operative wound, but that the string has disappeared. When everything is going smoothly the operator works a little faster than the stitcher.

Steel sacking needles, five inches long are best but the six-inch needle will do. Have a mechanic take the temper out, and give them a slight curve in the pointed one-third, with the curved part flattened and a cutting edge on each side and then re-tempered. Good steel needles are hard to get, the common ones will not do. The edge should be kept sharp enough to cut the suture string when the stitches are complete. This is the only good design for a needle. Such a one will go through the gastrocnemius tendon or plantar cushion without hard pressure and without a jerk.

After Treatment.- I dress liberally with pine tar thickened with flour according to the weather and let them drift on to good pasture direct from 
the corral; if they have to be moved it must be by good cowmen and very carefully. Confinement in a lot, or corral, I have never tried and should not care to.

Failures.- In about one percent I fail to get the deep ovary in a reasonable time and let them up.

I never spay pregnant heifers, stopping at once even if I have removed the left ovary before being aware of the condition.

Mortality.- When the last bunch I spayed was nearly finished the boys broke the leg of one in throwing her, but I think they were getting tired of bacon. In each of two lots that I spayed, one heifer was found dead about six weeks later, tion. This has been the total loss among upwards of 1100 heifers spayed during 1910 and 1911. I am not a quick operator, about 125 heifers a day being my limit, and the antiseptics, peritoneal fluid and sun are very hard on my skin. If my results have been good I attribute it to two things: first, reasonable cleanliness, and second, never using an instrument except on structures in plain view. 
Prospective. -Spaying heifers is becoming more and more popular on the ranges as the price of good beef increases over that of poorer grades. And resident veterinarians are doing a larger and larger percentage of this work which was formerly done almost exclusively by itinerant "specialists." No veterinarian locating in this region can afford to neglect spaying. 


\section{Oophorectomy in Cats*}

By G. E. Corwin, Jr., D. V. S., Canaan, Conn.

In performing feline oophorectomy and to insure a successful termination, the operation should differ materially from that usually performed upon bitches.

If the median-line operation is followed with cats, they will invariably remove, or at least disturb, the stitches and always give more or less trouble if not actually bringing on a fatal termination by this means. Upon cats the following technic for the operation will give best results:

Place the animal upon a slanted table, suspended by the hind legs and with the head lowered. Shave and disinfect the skin for the flank operation, either side, and when properly prepared anesthetize with ether.

In making the incision, first make it through the skin only, at a point anterior or posterior to

*Reprinted from the American Journal of Veterinary Medicine, December, 1911. 
the incision to be made in the muscle and peritoneum, then draw the skin incision to the point to be incised in the muscle.

Pick up, with the sterile, little finger, the fallopian tubes, which can readily be located without the use of the probe.

Draw the ovaries into the incision and remove. Return the tubes. Suture the muscles and peritoneum with the same interrupted, sterilized, catgut sutures, (two probably being enough) wipe dry with sterile absorbent cotton, and allow the skin incision to return to its proper position, which will cause the incision in the muscle to be entirely covered.

Do not put any suture in the skin incision, and the cat will do no other harm to it than licking. If sutures are used in the skin the cat will try to and usually does remove them. This is the primary cause of the median-line incision being so troublesome.

Do not use any carbolic preparation for disinfecting instruments to be used on a cat, nor use any such preparation for disinfecting the skin of these animals. I prefer chinosol. 


\section{Prolapsus Uteri : Its Successful Treatment*}

By A. J. Treman, D. V. M., Lake City, Ia.

On the morning of May 17, 1909, the phone wakened me uncomfortably early. Answering it, I learned that a farmer eight miles away wanted me to come, in a hurry, to his place. His answers to a few questions revealed that he had a mare with an eversion of the uterus. I directed him to get a large dishpan, fill it with clean hot water and place the everted mass into it and keep pouring hot water over it continually until I arrived.

When I arrived, I found a fine large five-yearold mare, with a complete eversion of the uterus and vagina. The pulse was weak and rapid, respirations hurried and distressed, the animal suffering considerable pain and quite weak; however the owner had carefully followed my instructions, and all hemorrhage was stopped, there was

*Reprinted from American Journal Veterinary Medicina, Dec., 1911. 
only moderate swelling of the mass, all the parts were reasonably clean and pliable and ready to be replaced. I immediately administered hypodermic stimulants and a small dose of aromatic spirits of ammonia, then proceeded to put myself in readiness to replace the organ. By the time this was done, I found that the patient was showing some effect from the stimulant.

With some difficulty we succeeded in getting the animal upon her feet, after which it was comparatively easy to replace the organ. With the return of the uterus, I inserted my hand and arm, as the Dutchman said, "Yust so far as I had any," and did what I could to restore all the parts to their natural position, meanwhile resisting the animal's straining. While my hand was still in the uterus, I had an assistant pump in a pail full of clean, hot, weak, disinfectant solution, this distended the uterus and horns to such an extent that I was able to restore all the parts to their normal position before the animal strained enough to throw out any of the solution. Then I siphoned off the liquid, injected more and siphoned it off, and kept on repeating this until 
the liquid was returned clean and there was a contraction of the uterus to such an extent that on withdrawing the hand I was able to siphon off practically all of the liquid. After this there was very little straining, and though I placed a truss in position it was not really necessary.

For several hours we had to be very faithful with our stimulants, and left generous doses of quinine, iron and strychnine to be given. On the second and third days following, we thoroughly flushed the uterus. This animal made a complete and uneventful recovery. I have had other cases that seemed hopeless make a nice recovery under this plan of treatment, two points of which I wish to emphasize.

First. Endeavoring to get the owner to thoroughly irrigate the prolapsed mass until I get to it.

Second. Filling the returned uterus with a hot, weak, disinfectant solution, to help in restoring all parts to their normal positions, and the repeated injections and siphoning of the solution until there is a strong contraction of the organ. This I find valuable in all cases where flushing is necessary. 


\section{Unusual Case of Obstetrics*}

By Dr. H. Jensen, Kansas City, Missouri

A gentleman called at my office stating that one of his valuable brood mares was having labor pains though she was not due to foal for a couple of months. A few doses of viburnum was prescribed and I heard nothing more about the matter.

About two months later I was called to his place and informed that in the forenoon this mare had given birth to a dead colt but kept on straining. On examination I found lodged in the os a scapula, and in the uterus I found the complete skeleton of another foal. All the soft structures were gone, the bones all disarticulated but no decomposition. The uterus had contracted considerably by this time, and a number of bones were firmly imbedded in the folds of the uterus, the womb was flushed a few times with antiseptic astringents and recovery of the mare followed.

\footnotetext{
*Reprinted from the Missouri Valley Veterinary Bulletin, August, 1909.
} 


\section{Proper Replacement of the Everted Uterus*}

By Sam Meader, D. V. S., Goff, Kansas

Eversion of the uterus is a very common occurrence in cows. Presumably the reason for the greater frequence of this condition in cows than in other animals is on account of the closer union in this animal between the placenta and the uterus. The peculiar arrangement in the cow by which the fetal coverings are in effect buttoned over the maternal cotyledons renders the separation of the afterbirth difficult and often attended by eversion of the uterus.

It is not the cleansing and replacing of the everted uterus, difficult though the operations are, that give the veterinarian the most trouble. It is keeping the uterus in place during the subsequent twelve to seventy-two hours that taxes his pa-

Reprinted from the Missouri Valley Veterinary Bulletin. August, 1909. 
tience, ability and ingenuity. Anodynes, suturing the vulva, the use of pessaries, surcingles, elevating the rear of the cow, all have their inconveniences and drawbacks and at times all fail.

We know in human kind what discomfort and pain and even alarming constitutional symptoms may result from even a comparatively slight displacement of the uterus. Having this in mind, it occurred to me that possibly the straining and consequent eversion of the uterus in the cow may be due to the traction upon and resulting displacement of the uterus by a too closely adherent placenta. And that the straining following the replacement of the organ was due to a failure on the part of the operator to get it into the normal position.

I have recently been trying the long-continued effect of gravity on the uterus filled with water and in the limited number of cases in which I had the opportunity to try it I have been pleased with the results. The following case will illustrate:

A cow that had everted her uterus after giving birth to a living calf. I found the animal in an old peach orchard that was grown up with under- 
brush. She had been walking about considerably and the uterus was very much lacerated, swollen and bleeding and thoroughly covered with feces and other dirt. It was a case where the indications were for continued straining. I cleaned up this uterus carefully in a warm three percent Creolin solution and with considerable difficulty replaced it after standing the cow in the stall with her hind feet about a foot higher than the front ones. She at once began to strain violently. With my arm inserted and with the aid of an assistant I commenced running in a weak solution of potassium permanganate and continued this for two hours, when her straining had nearly ceased. I instructed the owner to continue the irrigation for two hours longer. No other treatment was given. The following evening and the next morning the owner reported the cow doing fine. She did not strain any more and a week later she had fully recovered, all discharges having stopped. 


\section{Pervious Urachus*}

By C. L. Wilhite, D. V. S., Manilla, Ia.

During the latter part of the period of gestation the urine passes from the fetus through a canal or tube into the allantoid cavity (a space between the outer and inner folds of the placenta, the chorion and amnion, and lined with the middle fold of the allantois). This canal is called the urachus. When parturition begins this urine contained in the allantoid cavity is a part of the fluid that passes when the placental envelopes break.

Some authorities claim that pervious urachus is caused by a stricture of the urethra, but I have found such to be the cause in only a few of many cases that I have met. I believe it is caused by some freak of nature or a disease which prevents closure of the urachus at the bladder at birth or soon afterwards.

\footnotetext{
*Reprinted from the American Journal of Veterinary Medicine, December, 1911.
} 
In cases of pervious or persistent urachus the urine passes from the umbilicus in a stream or by drops during the act of urination and in occasional cases drips continuously. The hair around the umbilicus is generally wet. As the affliction gets older there is a catarrhal discharge and later pus. Occasionally, perhaps often, there is an infection present which if unmolested, works up the umbilical vein to the portal vein, then quickly to the liver, next the joints swell and the battle for life is on.

In 1907 I treated nine cases of pervious urachus which later developed septic arthritis. I used ligatures, cautery, injections, and, as the disease developed, several pounds of echinacea and other drugs too numerous to mention. Eight died of the nine and one lived but remained an unthrifty dwarf. I had about the same success, or rather failure, with my cases in 1908 and 1909.

In the spring of 1910 a veterinarian recommended pure oil of turpentine to me as a cure for sweeney and gave me a bottle to try. After seeing the swelling it caused I decided to try it on a case of pervious urachus to close the opening. 
I did so, and the leaking stopped in a few hours. Since then I have been using it continuously and have had only a few fatalities.

The treatment is as follows: Cast the patient without ropes so it may be let up quickly when through. Clip the hair around the umbilicus and wash with soap and water. Rub dry with a clean cloth. Cleanse the urachus with peroxide in a syringe with a long, small nozzle clear into the bladder. Wash the foam out with pure water. Get a few drops of pure oil of turpentine in the syringe, insert nozzle into the urachus to within an inch and a half of the bladder, as near as can be guessed. Inject turpentine slowly drawing the syringe out at the same time then let the patient up quickly. Inform the owner that the patient will do some scratching for a while, and that if the navel is leaking in three or four days the treatment will have to be repeated. Generally one treatment will suffice. Occasionally it takes two or three.

Females are more easily cured than males. If all the urine passes from the urachus there is a stricture of the urethra and it should be catheterized if possible. 


\section{Care of Navels in Newborn*}

By W. L. Williams, V. S., author of "Veterinary Obstetrics,"

"Surgical and Obstetric Operations," etc., Professor of Surgery in the New York State Veterinary College, Cornell University, Ithaca, New York

The care of the navel of the new-born domestic animal has been the subject of much difference of opinion amongst veterinarians and laymen and has been greatly influenced by comparison with the theories and practices of human obstetrics.

In general we accept as a truism in practice that a given course of action is alike applicable in all mammalia and hence that the correct method of dealing with the navel of a child will apply to all mammals. There are however some very important differences among mammals which serve to test the applicability in practice of this

- Reprinted from the American Journal of Veterinary Medicine. April, 1911. 
generally accepted theory. The navel cord of the foal and the calf are much more ample comparatively than that of the child or of the young of carnivora. The environment in which young are born differs widely, and the care bestowed upon the navel cord by the mother also varies greatly. The attitude of the young animal further changes conditions materially.

In herbivora the navel cord is normally ruptured by linear tension. It generally parts at a particularly frail point near the umbilicus. The cord being tensely stretched at the moment of parting, the umbilic arteries are much elongated and when they finally break, the proximate ends recoil, retracting into the abdominal cavity, drawing with them in an inverted state the surrounding loose perivascular tissue. The ruptured arterial stump is thus promptly withdrawn from the exterior where it might become infected, and the inverted, adherent connective tissue at once aids the contracting arterial stump in controlling the hemorrhage. The umbilic vein, or veins, collapse. The stump of the urachus retracts within the abdominal cavity between the two arterial 
stumps. Thus the vessels are promptly out of harm's way. The mother next gives the navel important attention by licking. This act is generally supposed to be purely cleansing but it is very much more. When intact, the naval cord is largely made up of the gelatinous, semi-fluid Whartonian gelatin which if left in the cord affords an excellent breeding ground for pathogenic microorganisms. This fluid, under normal conditions, slowly oozes from the stump of the cord and the latter finally desiccates, but the mother greatly hastens this process by a kind of tongue-massage. The fluid is forcibly pressed out during the licking process. This is tspecially empliasized in the cow with her rough, prehensile tongue, with which she exerts much force. In harmony with this, calves suffer far less from navel infection than do foals, whose navels get less tongue massage from the inother. In fact naval infection in calves is seen mostly in those early removed from their dams and this natural care of the navel by the mother prevented.

Ligation Harmful. - Many veterinarians and most veterinary obstetricians advise or practise 
the ligation of the navel cord of the new-born. They do not generally state their reasons therefor. It was advised by Nocard for the prevention of "white scours" in calves, though just why it should prevent this dreaded disease is not clear. It certainly can not prevent the entrance of infection through the navel. We may limit infection to some extent by a ligature around a living tissue, as when we ligate a hernial sac, but even there our power is vague. In that case however we apply the ligature to living, active tissues, cutting off nutrition on one side of the ligature and leaving it comparatively undisturbed on the other side, where a protective wall against any threatening infection is quickly established. In the navel cord it is quite otherwise. The interruption of the placental circulation and establishment of the pulmonary functions renders the umbilic stump a dead mass of tissue. The arterial stumps and the urachus have retracted and are no longer in the cord, while the vein or veins have wholly ceased to function and are dead. The remaining umbilic tissues, the amniotic sheath of the cord, the areolar tissue and Wharton's jelly 
included within it are dead and all that now remains of the navel stump must ooze away, desiccate or decay. It must be clear to anyone that a ligature applied around a columnar mass of dead tissues can not prevent the invasion of bacteria on either side of the ligature; it can not hold either the distal or proximal tissue against bacterial invasion.

Fortunately for the calf the navel cord usually ruptures before the birth act has been completed and the arterial and urachal stumps have retracted within the abdomen out of reach of the meddler. In the foal the navel cord is longer and a ligature may be applied before it is ruptured and the arteries and urachus become incarcerated and their infection rendered probable.

The most serious objection to ligation lies in the fact that the ligature imprisons within the amniotic sheath all of Wharton's jelly and all blood which may ooze from the withdrawn arterial stumps if they have retracted. If the arteries have not retracted and are caught in the ligature a large blood clot is imprisoned just above the ligature; any urine oozing from the retracted 
urachus is also imprisoned, and any blood remaining in the umbilic vein or veins is likewise retained. This retention of liquids within the dead tissues serves to invite infection and is in direct conflict with surgical principles, one of the most fundamental rules of which is the ample provision of freedrainage for all inactive useless fluids.

Sources of Infection.-The ligation of the navels of new born domestic animals is rarely carried out under aseptic or antiseptic precautions of even a crude character; usually the hands of the ligator, and the ligature are bearers of infection. After meeting this danger the foal or calf spends much of its time with the navel stump in contact with dung or other filth. When standing the moist navel stump is a favorite feeding place for flies, bearing various infections.

But it is held, the human obstetrician ligates the navel stump and why should not we also? The cases are not parallel. The human obstetrician ligates the cord under careful antisepsis, after expressing the jelly of Wharton and other fluids, then applies antiseptic or aseptic dressings to the wound which is retained in place by a 
clean bandage and the infant is kept in a dorsal recumbency with no opportunity for fecal, urinal or other soiling of the dead stump.

Navel Hemorrhage Not Serious. - If the ligation of the navel cannot prevent infection there would seem to be but two other reasons for the procedure, hemostasis and fashion. In an extensive obstetric practice extending over thirty-two years the writer has not observed fatal or important naval hemorrhage and has learned of but one case from his fellow veterinarians. That one case was in a foal, belonging to a veterinarian who ligated the cord. Apparently he had excised the cord too long, the excised arterial stumps retracted up through the ligature and failed to close as the ruptured end would have done, the escaping blood accumulated above the ligature, distending the amniotic sheath of the cord, pushed it off and permitted the fatal hemorrhage.

Fatal umbilic hemorrhage rarely, if ever, follows the normal division of the umbilic cord by linear tension (herbivora) or by gnawing (carnivora). Ligation is wholly superfiuous from a hemostatic standpoint and if accompanied by ex- 
cision of the cord adds greatly to the danger from hemorrhage because an excised artery bleeds more freely than an artery severed by any other method. Clinically an artery is generally not held by a ligature about the cord, especially if the cord is divided reasonably short. As that is the case in most navel ligations the control of the hemorrhage is due, not to the ligation but to autohemostasis, in the ordinary course of the normal physiologic powers of the umbilic arteries.

If we examine the question clinically we find that the above conclusions are borne out by everyday experience.

Prevention of Infection.- Foal after foal perishes from navel infection and a far larger percentage of foals succumb with, than without, ligation. On the other hand, navel infection is uniformly prevented by open antiseptic, desiccant handling of the navel. If the normally ruptured navel, or the navel artificially divided in a manner simulating the natural method (linear tension, scraping, ecrasement) under antiseptic precautions - the jelly of Wharton pressed out and a desiccant antiseptic applied navel infection is 
promptly and effectively barred. If the freshly ruptured navel, from which the Wharton's jelly and other fluids have been expressed, is immersed in a 1-1000 corrosive sublimate solution for fifteen to twenty minutes it will have become well disinfected. This may be conveniently accomplished by filling a cup with a solution and pressing it against the abdominal floor around the navel, thus immersing the navel stump within the solution. After this thorough disinfection, desiccation of the stump may be hastened and the sealing of the wound against infection insured by dusting the stump over with a powder consisting of equal parts of gum camphor, alum and starch, finely powdered. This may be repeated every thirty minutes until the desiccation is complete and a hard, dry antiseptic scab is the sole remnant of the umbilic stump; the wound is sealed and infection is excluded.

If sure that the navel is reasonably clean, the immersion of the stump in the corrosive sublimate solution may be safely omitted and the desiccating antiseptic powder at once applied. Or after the cord has been ruptured and the fluids expressed 
from the stump it may be efficiently disinfected and desiccated by the application of tincture of iodine, but this needs be done with great care, lest the skin about the navel be blistered. Iodine is not wholly safe in the hands of the layman, and it is the layman who must usually care for the navel of the new-born under directions from the veterinarian.

While we frequently see glowing accounts of how navel infection in new-born animals has been cured by this or that veterinarian by bacterins or other very remarkable remedies, the conservative veterinarian would as yet prefer secure prophylaxis to glorious, sensational cures. He may not get as much money out of it, but he will gain much in satisfaction and in professional standing. 


\section{Superfetation With Report of a Case*}

By R. F. Bourne, B. Sc., D. V. S., Professor of Physiology, Kansas City Veterinary College

By the term superfetation is meant conception in an animal already pregnant before the termination of the primary period of gestation. This term should not be confused with superfecundation-the fertilization of two or more ova of the same ovulation by separate copulative acts.

Opportunity for erroneous conclusions in cases of this character is so great that some authorities have doubted the possibility of its occurrence; but there are recorded, several indisputable cases of superfetation and doubtless some who read this may recall occurrences in their own experience. However, these instances seem to be

\footnotetext{
-Reprinted from the Missouri Valley Veterinary Bulletin, July, 1909.
} 
exceedingly rare; far rarer than cases where double conception has resulted from connection with two different males at intervals separated only by a few hours. Fleming records cases where women have borne twins, one white and one mulatto, from copulation with a white man following that with a negro or vice versa, and similar cases where a horse and a mule colt were delivered at one birth when service with a horse and a jack was had on the same day. These are cases of superfecundation.

The more remarkable instances are those in which conception has occurred from two copulative acts, weeks or months apart (superfetation), and where each fetus is carried for the full period of gestation. One of these cases occurred in New York in 1876. A five-year-old mare bore a fullydeveloped, well-formed dead colt on February twenty and on the second of April another sound, healthy fully-developed live colt. Other cases in which two fetuses in different stages of development have been delivered at one birth are more frequent. The following case of this kind recently came under my observation. 
I was called by a farmer who reported that he had a mare which had foaled and which was not behaving properly. Upon my arrival about nine p. $m$., I found a black, twelve-year-old mare exhibiting symptoms of mild colic and treated her accordingly. Vaginal exploration revealed conditions normally present after parturition. The owner then related the following history: The mare had been purchased by him five months before, and was said to be in foal from a horse or jack, she having been bred to both. She had been served first by the jack, and in order to insure conception was returned, some three weeks later, to the town where the jack was kept. In the meantime, however, the jack had been removed and the owner allowed the mare to be served by a percheron stallion. So far as the present owner knows no subsequent service was had and the opportunities for it seem very remote, judging from the conditions under which most farm mares are kept.

A few hours prior to my call the mare gave uneventful birth to two colts, one an immature mule and shortly after a well-formed full-term 
horse colt. Both were dead. The mule's body was not yet completely covered with hair and its size was not more than one-third that of the full-term foal.

The only explanation I can offer as to the immature state of this foal was that it had been carried dead for some months and had resisted decomposition and mummification until normal conditions had delivered it along with the horse colt. The carrying of a dead fetus for this length of time is not rare and unless service was had with a jack at a later period than that with the stallion, we must accept some such explanation. Parturition occurred about two weeks before the normal period of gestation, for the horse colt, had expired. 


\section{Atresia Ani *}

By A. T. Kinsley, M. Sc., D. V. S., Pathologist, Kansas City

Veterinary College, Author of "Veterinary Pathology" etc.

During the embryonic stage of intrauterine life the specialized tissues and organs are formed. The fetal period is the time during which the structures formed in the embryonic stage grow and develop. At birth the young of a given species are of a definite shape, contour and type; the form or type which is most common is accepted as normal; and deviations from the normal are designated malformations, anomalies or developmental errors. Many new strains and breeds of live stock have been the result of developmental errors becoming a fixed peculiarity. Thus the polled cattle, the Boston bull-dog, the Mexican (hairless) dog, and the five-toed chicken had their origin.

A variety of malformations are of course seen at the season when veterinarians are called

\footnotetext{
-Reprinted from the Missonri Valley Veterinary Bulletin, June, 1908.
} 
to attend cases of parturition. Obstetrical cases in addition to the general practice entails the expenditure of considerable energy and the practitioner may not be as careful and observing in some cases as he should be.

Atresia ani is a malformation that is not rare and is frequently not observed by the attending obstetrician. This malformation is the result of imperfect union of tissues. During the earlier stages of development, i. e., the embryonic period, the digestive tract from the pharynx to the rectum inclusive is formed from the entodermal tube. The anus is formed in the fetal stage by invagination of the skin surface, the anus and rectum are at this stage separated by a thin membrane. Normally the rectal and anal walls fuse, the separating membrane is absorbed and thus there is produced a continuous canal.

Failure of the anal invagination, failure of fusion of the anal and rectal walls, or failure of solution of the separating membrane would result in an imperforation and there would be no outlet for the escape of the contents of the digestive tube. 
The communication between the bladder and intestine may persist thus allowing the fecal matter to discharge into the bladder. A communication may also occur between the intestine and urethra or the intestine and vagina.

The young of any domestic animal could not survive long without evacuation of the contents of the digestive tube. Atresia ani occurs most frequently in pigs and calves, though colts and other animals are not exempt. This malformation is usually easily relieved by an operation the nature of which depends upon the specific condition existing. If there has been failure of absorption of the separating membrane it may be ruptured by the use of a blunt instrument no further treatment being necessary. In those cases resulting from the failure of fusion of the rectal and anal walls, the intervening tissue should be very carefully dissected and the walls of the rectum and anus approximated and sutured. When there has been a failure of cutaneous invagination a crucial incision should be made through the skin and the intervening tissues bluntly dissected to the lumen of the rectum, then 
the mucous membrane of the rectum should be pulled outward, sutured to the skin or margins of the opening made by the dissection so that the mucous membrane and skin are continuous and form a lining for the artificial opening.

If there is a communication between the intestine and the bladder urethra, or vagina it should be closed by a plastic operation and the external opening made as indicated above. 


\section{Treatment of Contracted Tendons in Foals*}

By James Smellie, M. D. C., Eureka, Illinois

The title of this paper should really be "Treatment of Contracted Tendons and Ligaments in Young Colts," because in the majority of cases the ligaments are just as much at fault as are the tendons. The contraction of one or both of these structures is a condition that the country practitioner meets very often, and in most cases, it is quite serious.

Every year we see a number of colts born with such marked contraction of the flexor tendons and posterior ligaments of the forelegs that the animal knuckles over on the fetlock joint, and is unable to extend the phalanges. The condition, if allowed to continue very long, causes an undue

*Reprinted from the Missouri Valley Veterinary Bulletin, Feb., 1910. 
extension of the extensor pedis tendon, and also of the anterior part of the capsular ligament. This, combined with the bruising of the skin, from contact with the ground sets up a thickening over the joint that is apt to remain.

In some colts the flexure is at the carpus. In such cases the metacarpal muscles and check ligaments are most affected; in some cases delivery is effected with the front legs flexed. I have seen a few cases of this condition in the hind legs, with the contractions at the fetlock and the flexor tendons most affected.

Ftiology.- This malformation is caused, I believe, by the limbs becoming flexed in utero and for some inexplicable reason, remaining that way too long. It may possibly be hereditary in some cases, when one or both parents have upright shoulders and short straight pasterns. I know of a mare of such conformation that has had two colts in succession, sired by the same horse, that knuckled completely over on one front fetlock, and could touch the ground with only the toe of the other leg. Her colts were sound when sired by another horse. 
Treatment.- Only in those cases where the colt was lively and energetic have I ever been successful in my treatment of them. When the animal is young the ligaments and tendons will stretch a long way if the limbs can be brought into position so the animal can use them.

In the hind leg, it is comparatively easy, provided the flexors are not too short. I make a bar shoe exactly the size of the foot with a projection coming straight forward about three inches, then turning it up to form a brace to which the limb is strapped. The fetlock joint forms an admirable fulcrum for the brace, and every time the animal stands up it stretches the tendon, which soon allows the foot to assume its natural position. If there is too much contraction section of the perforans has to be performed.

In the front leg, treatment is more difficult, because all joints flex in one direction. I make a bar shoe exactly the size of the foot with a forked projection in front extending from two to four inches. If the joint is weak and inclined to break over outward, it may be necessary to weld on a spur on the outside of the shoe. It is necessary 
to raise the points of those projections and give the foot a rolling motion backwards. The feet are very soft for a few days, but generally about the third or fourth day, the hoof is hard enough to hold the nails.

In a few cases where the joints were weak, I have had to put on a plaster cast for a few days to stiffen the joints enough so the animal could get in the habit of using its feet.

When the carpus is affected, tenotomy of the metacarpi medius and the perforans tendons has to be performed. 


\title{
Minor Means of Restraint
}

\author{
By D. M. Campbell, D. V. S., Chicago
}

The veterinarian and particularly the young veterinarian who can control his patient with the least expenditure of time and energy on his own part as well as with the greatest measure of safety to himself and to the animal is in a fair way not only to do better surgery because of this perfect control but to win favor with his clients and a reputation for "horse sense" which is so necessary to one who would be considered by stockmen a master in his profession.

On the other hand the inability to cast, throw or tie an animal as well as the owner himself can, is one of the greatest handicaps a veterinarian can have, not only because of the actual inconvenience to which he is subjected but also because of the lessened respect-the almost contempt the owner will have for a veterinarian on this account alone. A veterinarian's clients ex- 
pect him to know more about their animals than they themselves do and regard with suspicion the knowledge of a veterinarian who knows less than they about controlling animals.

An ever-present example of the above may be seen in the regard most horsemen have for the incompetent veterinary dentist who, though he knows very little about a horse's teeth and their abnormalities, from long practice is able to handle the horse while dressing the teeth in a very skillful manner, and to float the teeth quickly, without the use of a speculum and with almost no resistance from the patient. Contrast the effect of such "smooth work" with the bunglesome method of some competent though unpracticed veterinarian who has done little of this work and whose final results when the work is completed are infinitely better than the other, and one may see at once how much horsemen appreciate "horse sense"- "handiness."

Nothing else is quite equal to ingenuity and of course common sense in handling animals. To some extent every case presents its own problem; but a few suggestions that are capable of 
modification to apply to a large variety of circumstances may be useful, particularly to the recent graduate in veterinary medicine whose boyhood and early manhood was not spent on a farm or among animals.

To Handle the Hind Feet of an Unbroken Horse*.-Take a piece of five-eighths inch rope with a noose at one end that will not slip and large enough to go around the neck near the shoulder, then put a half-hitch around the body, just back of where the backband of a harness comes, then take on back through a strap buckled firmly around the root of the tail. To this fix a ring or a knot and connect a small block-andtackle with it and to a hobble on the foot to be raised. A ten-year-old boy can do the rest.

To Pass the Knisely Stomach Tube*-Draw very tightly around the nose a common harne strap, this is placed just high enough so as not to interfere with the animal's breathing. Then lubricate the tube and pass it in through the interdental space and down the esophagus as usual.

\footnotetext{
*By H. B. Treman, D. V. M., Rockwell City, Iowa; reprinted from the Missouri Valley Veterinary Bulletin, July, 1909.
} 
The animal breathes much easier than it does when a mouth speculum is used and consequently does not resist the operation so strenuously. Besides, the little strap is far more convenient to carry than a heavy speculum. I also think that the tube is less liable to enter the trachea when so used than it is with the mouth held open.

Restraint for Cattle.-I have been surprised to find some veterinarians unfamiliar with the almost universal means or method for throwing a cow, and many others that though familar with this means of throwing the animal have thought that after the animal is thrown it needs further tying to hold it down for various operations. This is not the case. Two ropes, one with which to tie the animal by the head and another single rope twenty-five feet long are sufficient for one man to throw and hold the largest bull for an operation for actinomycosis or for putting a ring in his nose or for almost any other operation except upon the feet and legs.

To cast and control cattle where one has not the assistance of trained cow men and cow horses or ponies, select a piece of sloping ground, the 
steeper the slope the better within reasonable limits. Tie the animal by the horns or with a halter at the ground to a strong stake or post, then loop one end of a strong rope around the animal's neck near the shoulder. Tie the loop so that it will not slip. Take a "half hitch" or loop behind the shoulder and another just in front of the anterior angle of the ilium and the udder or scrotum. The first of these "half hitches" is not essential but the second is very necessary. Then get the animal to stand back from the post to which it is tied as far as possible and pull steadily and strongly upon the rope, determining the side upon which you want the animal to lie by pulling at a slight angle.

If in falling the animal should slacken the rope by which it is tied at the head it must be allowed to rise and the throwing repeated and kept up until the animal falls with the head rope taut. With a very little experience the operator will be able to accomplish this quickly, usually at the first throw, and in no case requiring more than two attempts. 
After the animal falls keep the rope tight and it will very soon cease to attempt to rise. Then have an assistant take the rope and pull strongly upon it almost at a right-angle to the long axis of the animal's body, standing just a little bit back of where a right angle line would run. Allow the legs to remain free and the animal to use them as much as it likes. In this way the struggling will do no harm and even cows heavy with calf may be operated upon for lump jaw or other ailments without the slightest danger of producing an abortion or otherwise injuring them.

With the animal in this condition an operation upon the fore feet or fore legs offers little diffculty. Simply flex the legs strongly and tie them there. The hind feet offer a little more difficulty, particularly if it is desirable to keep an animal in an advanced stage of pregnancy from injuring itself through struggling, but the ingenious veterinarian will have little difficulty.

\section{To Control Cattle in a Standing Position.*} -For castrating old bulls, or for giving them

*Reprinted from the American Journal of Veterinary Medicine, July, 1911. 
tuberculin injections, when they evince a desire to kick and for many other operations not upon the head, cattle may be restrained without going to the trouble to cast them, by the following very simple expedient:

Have the animal securely tied by the head and take two strong poles-fence rails serve admirably, and cross them beneath the animal. Two assistants should then lift upon the rails, so that the animal rests, just in front of the udder or scrotum, a part of the weight upon the rails crossed saw-buck fashion with the long ends up.

To Break a Horse From Pulling Back.One may often curry much favor with his clients by showing them how to break a horse from pulling back upon the halter. This is a very simple matter and one with which every veterinarian should be familiar.

Take any strong rope but preferably a new three-eighth-inch hard twisted one such as is used for lariats and make a small, non-slipping loop in one end. Place the rope about the horse's body just posterior to the fore legs, run the free end of the rope through this loop, take it between the 
forelegs and forward through the ring in the head stall of the halter. Tie to the manger or a post or anything solid, just short enough so that when the animal backs as far as this rope will let him he will still lack about a foot of taking up the slack in the halter rope and then leave him to his own salvation, or if he should refuse to pull, after a reasonable time, induce him to do so by "shooing" him or slapping him over the head with a sack or something of that kind. It is best, however, to let him get caught at his old trick of his own initiation. The tightening of the rope about the chest will frighten the animal very much and he will at once spring forward and will not repeat the process until he forgets about it. Three or four experiences of this kind are usually sufficient to break the habit in the worst puller. 


\title{
The Treatment of the Injured Hand *
}

\section{How to Cleanse it and How to Examine it}

\author{
By Ralph St. J. Perry, M. D., Santa Fe, Isle of Pines, Cuba
}

[EDITOR's NOTE.-Minor injuries to the hands that are infected during their work and become serious are of such common occurrence among veterinarians that no apology is required for presenting this excellent article, a chapter from Dr. Perry's book on "The Injured Hand," here even though it deals with no phase of veterinary surgery. The principles here given apply alike to minor surgery of both man and animals. Dr. L. A. Merillat, the most widely read surgeon among veterinarians has pronounced this article the best "surgery" that has ever appeared in a veterinary publication.]

Probably every accidental wound is an infected wound. Out of several hundred of such injuries only two were found to be noninfected when subjected to bacteriologic tests. The infection usually is coincident with the injury, and it is doubtful whether any method of wound cleansing has yet been devised which will surely and immediately eliminate this primary infection.

\footnotetext{
*Reprinted from the American Journal of Veterinary Medicine, November, 1910.
} 
The rapidity with which infection can spread from one portion of a wound to another, or from an infected wound to adjacent healthy tissues, is startling. Schimmelbusch inoculated the tip of a mouse's tail with anthrax germs and ten minutes later cut off the tail at its root; the mouse died of anthrax. Reichel maintains that one minute after inoculation the most thorough antiseptic treatment is powerless to prevent infection. What, then, can be expected where an injury is rarely seen by the surgeon until fifteen minutes after its infliction, while oftener it is thirty minutes or an hour?

Observation and experiment have proved that powerful antiseptics devitalize the tissues and do more harm than good. This is particularly true of carbolic acid, cresylic acid and corrosive sublimate. These are cited because they are the ones most commonly used by the profession and laity, and the most dangerous. If it be true that these antiseptics cannot prevent or counteract infection and that they by their destructive action upon the tissues really tend to create a field for the development of germs, why use them at all? The 
question is a proper one, and my answer is, Don't!

Don't use carbolic acid.

Don't use cresylic acid!

Don't use corrosive sublimate!

But if not these, what would you use? It is desirable to use an antiseptic which will prevent further infection and the further development of infecting germs already in the wound. We want a protective and preventive which is not caustic or irritating, something that will cleanse without doing injury and which will guard against the assaults of extraneous germs.

Surgical Cleansing of the Injured Hand.The vast majority of injured hands are those of mechanics and laboring men and come to the surgeon smeared with machine grease, paint, varnish, mud, mortar, sawdust, flour, tobacco quids, cobwebs, and many other substances which are a part of honest labor or which have been applied to the wound in well-meant but misguided efforts to stop bleeding or ease pain. To remove these substances I use three applications:

Warm saline solution,

Gasolin, plain and iodized,

Warm solution of mercuric cyanide. 
The saline solution (a teaspoonful of clean table salt to each pint of boiled water) is familiar to all and needs no special mention. It is used to remove the grosser portions of the dirt-the term "dirt" being here employed as applying to all matter out of place.

Use Gasolin to Remove Oil and Grease.In cases where the injured parts are soiled with machine grease, paint, oil, varnish and similar substances not removable by water, resort is had to ordinary commercial gasolin. The use of gasolin for this purpose, while not general, is not a novelty. I have so utilized it for more than twenty-five years; others have used it, and it is now quite generally used by surgeons who have much factory, machine-shop or railroad surgery. While acting as a solvent for fats, oils, gums, wax and resins, it is, to a certain extent, antiseptic, besides causing no pain; hence it makes an excellent detergent when the parts are besmeared with such substances.

The addition of resublimed iodine to the gasolin (one dram to the pint) increases its antiseptic powers without affecting its detergency. Iodized 
gasolin should be freshly prepared, in small quantities, at the time of use.

To use the gasolin, pour it directly upon the wound from a small-mouth bottle, letting it wash all over portions of the injury; also make a mop of absorbent cotton or gauze, saturate with the gasolin and gently rub over the parts until cleansed. If the dirt be unusually tenacioús, a soft tooth-brush may be used. The body-heat causes the gasolin to evaporate from the surface, leaving the parts clean and dry.

Gasolin is almost as efficient as hydrogen peroxide in breaking up adherent clots, and is not painful.

By way of caution: The surgeon must remember that gasolin vapor is highly inflammable, even explosive; also, that if it gets into the eye, ear or closed cavities it may cause pain, just as do ether, chloroform and other quickly volatilizing liquids. Benzin may be substituted in an emergency.

Mercuric Cyanide Solution. - The mercuriccyanide solution has been a favorite cleansing solution with me for many years. Since I first called attention to its use in antiseptic surgery (in 1898) 
its use has become quite general because of the following advantages:

Mercuric cyanide is freely soluble in hot or cold water, and in alcohol; it does not stain the fingernails or give rise to eczema or other inflammations of the skin; it does not coagulate albumen in blood, mucus, purulent or other discharges or excretions; it is not precipitated or decomposed by soap; it does not corrode steel, nickel or silver; it can be used in any kind of a vessel-enameled, porcelain, tin, papier-mâché or wooden; it is inexpensive.

Some of my critics, especially the laboratory bacteriologists, have maintained that mercuric cyanide is not an antiseptic, that it will not inhibit germ growth; but to these I say that I have used it for now more than ten years, and the results have been more satisfactory than I obtained from other antiseptics. The practical experience of many other surgeons corroborates my own.

Other critics say it is too dangerous an antiseptic for general use, that its lethal effects are too sudden should one of the laity accidentally swallow some of it. But these should remember 
that this agent is for the use of surgeons and not of the laity, that the latter have no business with it, and that in the hands of a competent surgeon it is as safe as an amputating knife or other instrument.

In cleansing the parts around a wound it is sometimes desirable to use soap, and I have found "mechanics' soap," a coconut-oil soap plus fine sand, or rather stone, as good as any of the higher-priced antiseptic soaps. If desirable, an antiseptic solution may be used as a rinsing application after the soap.

Hydrogen peroxide I do not often use in primary cleansings, since little difficulty has ever been experienced by using the methods just described. Before attempting to cleanse a wound always apply a tourniquet to prevent further bleeding.

Examination of Injuries. - Having cleansed the wound of all extraneous matters, the surgeon should see to it that his own hands are again rendered surgically clean, after which he may proceed to examine into the nature and extent of the injuries. 
In making such examination, use the fingers rather than instruments, as much as possible, but gently, very gently, depending upon the tactile sense to determine what conditions exist, using the eyes, ears and nose as aids to the sense of touch.

The tactus eruditus, the educated sense of touch, is nowhere of greater importance than in surgical practice. While manual dexterity is advantageous in the technic and mechanical work of the profession, the great importance of a correct diagnosis speaks for the value of the educated touch. This tactus eruditus can be rapidly and readily acquired in the everyday experiences if the student or practitioner will only make the effort to determine size, shape, surface qualities and other physical attributes by the touch, thus learning to identify objects by their "feel."

Care in Handling.-Simple superficial wounds will require very little handling; incisions, punctures and lacerations due to known causes call for nothing more than a careful inspection. Where the presence of a splinter of wood, metal or glass is suspected, a very gentle digital examination 
will discover the foreign body more readily that a rough examination or probing with a metalli probe.

In searching for deeply imbedded foreig bodies, use the probe as little as possible. If thi body be a bullet, needle or other metallic substance use the x-ray. The indiscriminate use of thi probe in bullet wounds, fractures, necroses, sin. uses, etc., cannot be too strongly condemned Modern methods are so much more superior, defi. nite and less dangerous that the probe has beer to a large extent rendered obsolete and shoulc only be resorted to when other methods are not at command.

The tactile sense should easily detect fractures and dislocations if the parts be not swollen toc much, and in open wounds of joints should be able to determine the condition of the cartilage surfaces. Should it be necessary to use instruments in examining a wound, they should be sterilized.

The Sense of Smell.-The sense, of smell if of much assistance in determining the condition of wounds, as all emit characteristic odors of fresh blood, "healthy" pus, tissue necrosis, etc., 
according to their age, stage of healing, infections and dressings.

The odors given forth by wounds may be more or less modified by those natural to the body, due to the perspiration and other cutaneous secretions. In ordinary persons this odor is sulphurous, especially so in red-haired and freckled individuals; brunettes possess a prussic-acid and blondes a feeble musk odor; fat persons have a more pronounced odor than lean ones, the former frequently having an oily odor due to excessive fatty acids in the sebaceous secretions. Race, sex, age, personal cleanliness and complicating skin diseases also influence the odors of wounds.

Various foods and some medicines taken internally impart odors to the skin secretions which may modify the normal wound odors, and local applications to the seat of injury may be expected to do so.

A recent undressed wound presents the odor of fresh blood, which, if there be union by first intention, gives way to that of the dressings applied. A wound bathed in pus from healthy granulations gives a characteristic odor which is not 
offensive; if, however, there be necrosis, decomposition of the discharges or maceration of callosities or scabs, there is a very pronounced and disagreeable odor of putrefaction. I have noticed in wounds in syphilitics a characteristic odor, also in those made by ice-cutting tools, and in human bites. Wounds infected with glanders or diphtheria present the peculiar odors of those diseases. All these things the experienced surgeon bears in mind.

Macroscopic inspection of wounds will reveal much concerning their extent and condition, but the eye must be supported by the touch, as there are many things in an injury which the eye cannot detect and many appearances which are highly deceptive. In cases where there is doubt as to the nature of infection resort is had to bacteriologic culture and miscroscopic examinations.

A most important adjunct to the ocular examination of injuries is the $\mathrm{x}$-ray apparatus whereby fractures, dislocations, bone inflammations and necrosis can be definitely determined and metallie bodies located. 






